\title{
MZB1 is a GRP94 cochaperone that enables proper immunoglobulin heavy chain biosynthesis upon ER stress
}

\author{
Marc Rosenbaum, Virginia Andreani, ${ }^{1}$ Tanya Kapoor, ${ }^{1}$ Simone Herp, Henrik Flach, \\ Marlena Duchniewicz, and Rudolf Grosschedl ${ }^{2}$ \\ Department of Cellular and Molecular Immunology, Max Planck Institute of Immunobiology and Epigenetics, Freiburg 79108, \\ Germany
}

\begin{abstract}
MZB1 (pERp1) is a B-cell-specific and endoplasmic reticulum (ER)-localized protein implicated in antibody secretion and integrin-mediated cell adhesion. Here, we examine the role of MZB1 in vivo by conditional gene inactivation in the mouse germline and at different stages of B lymphopoiesis. Deletion of MZB1 impairs humoral immune responses and antibody secretion in plasma cells that naturally undergo ER stress. In addition, we found that experimental induction of ER stress by tunicamycin injections in mice results in a block of pro-B-cell to preB-cell differentiation specifically in $\mathrm{Mzb1}^{-/-}$mice. A similar developmental block was observed in $\mathrm{Mzb1}^{\mathrm{fl} / f 1} \mathrm{mb1} 1^{\mathrm{Cre}}$ mice, whereby a Cre recombinase-induced genotoxic stress unmasks a role for MZB1 in the surface expression of immunoglobulin $\mu$ heavy chains ( $\mu \mathrm{HCs}$ ). MZB1 associates directly with the substrate-specific chaperone GRP94 (also called HSP90B1 or gp96) in an ATP-sensitive manner and is required for the interaction of GRP94 with $\mu$ HCs upon ER stress. Thus, MZB1 seems to act as a substrate-specific cochaperone of GRP94 that enables proper biosynthesis of $\mu \mathrm{HCs}$ under conditions of ER stress.
\end{abstract}

[Keywords: MZB1; B lymphopoiesis; antibody secretion; ER stress; GRP94; cochaperone]

Supplemental material is available for this article.

Received February 27, 2014; revised version accepted May 1, 2014.

B lymphopoiesis is a well-studied paradigm for a terminal differentiation process in which hematopoietic stem cells (HSCs) develop through multiple stages to finally generate highly specialized antibody-secreting plasma cells. Differentiation of murine HSCs via lineage-restricted common lymphoid progenitors (CLPs) generates pro-B cells that proliferate in response to interleukin-7 (IL-7) signaling and initiate the rearrangement of the immunoglobulin heavy chain (Igh) locus. Productive Igh rearrangement and assembly of the $\mu$ heavy chain $(\mu \mathrm{HC})$ with the Ig surrogate light chains $\lambda 5$ and $V_{\text {preB }}$ result in the expression of a functional pre-B-cell receptor (pre-BCR) and generation of pre-B cells that are still responsive to IL7 signaling (von Boehmer and Melchers 2010; Herzog and Jumaa 2012). Signaling via the pre-BCR triggers several rounds of cell division and the rearrangement of Ig light chain genes, which leads to the surface expression of the IgM BCR and generation of immature B cells that migrate from the bone marrow to the spleen. In the periphery,

\footnotetext{
${ }^{1}$ These authors contributed equally to this work.

${ }^{2}$ Corresponding author

E-mail grosschedl@ie-freiburg.mpg.de

Article is online at http://www.genesdev.org/cgi/doi/10.1101/gad.240762.114.

Freely available online through the Genes \& Development Open Access option.
}

immature B cells further differentiate via transitional B cell stages to mature $B$ cells that respond to antigenic stimulation by terminal differentiation (Allman and Pillai 2008).

Surface expression and function of the pre-BCR require the endoplasmic reticulum (ER)-resident chaperones $\mathrm{BiP}$ (HSPA5) and GRP94 (also called HSP90B1 or gp96), which assist protein folding by recognizing exposed hydrophobic patches (Haas and Wabl 1983; Melnick et al. 1994; Meunier et al. 2002). Moreover, the folding of proteins with disulfide bonds, such as Igs, requires the action of protein disulfide isomerases (PDIs) that control disulfide-linked IgM assembly by recognizing free cysteines and aberrant disulfide bonds (Lilie et al. 1994; Vavassori et al. 2013). Despite the function of elaborate protein-folding machineries in the ER, misfolded proteins can accumulate in the ER and result in a cellular stress, known as unfolded protein response (UPR) (Todd et al. 2008). The UPR results in the recruitment of $\mathrm{BiP}$ to unfolded proteins and dissociation of BiP from the ER

(C) 2014 Rosenbaum et al. This article, published in Genes \& Development, is available under a Creative Commons License (AttributionNonCommercial 4.0 International), as described at http://creativecommons. org/licenses/by-nc/4.0/. 
transmembrame protein inositol-required enzyme 1 (IRE1) (Bertolotti et al. 2000). This dissociation of BiP and IRE1 leads to an unconventional mRNA processing and excision of 26 nucleotides (nt) from $X b p 1$ mRNA to generate spliced $X b p 1(X b p 1 s)$, which encodes a nuclear transcription factor (Yoshida et al. 2001; Calfon et al. 2002). The UPR also plays a major role in the terminal differentiation process of $\mathrm{B}$ cells into plasma cells, which is accompanied by the expansion of the ER and the upregulation of proteins involved in folding and secretion (Iwakoshi et al. 2003; Shaffer et al. 2004). Stimulation of the BCR leads to the proteasomal degradation of BCL6 (Niu et al. 1998) and up-regulation of IRF4, Blimp1, and $\mathrm{XBP} 1$, which results in terminal differentiation of $\mathrm{B}$ cells, expansion of the ER, and the expression of genes related to the UPR, including BiP and GRP94 (van Anken et al. 2003; Shaffer et al. 2004; Taubenheim et al. 2012). Increased Ig production also drives a feed-forward circuit by triggering IRE1 activation and enhancing generation of $\mathrm{Xbp} 1 \mathrm{~s}$ (Reimold et al. 2001).

$\mathrm{B}$ cells in the periphery consist of multiple cell populations that differ in the phenotype and responsiveness to antigenic stimulation. In particular, cells residing in the marginal zone (MZ) of the spleen, termed MZ B cells, and B-1 cells found in the peritoneum quickly differentiate into antibody-secreting cells and produce polyreactive antibodies (Martin et al. 2001). In contrast to these cells, which have also been termed "innate-like" B cells, the majority of conventional B cells, termed follicular B (FoB) cells, produce specific antibodies with much slower kinetics. In an attempt to understand the phenotypic differences between peripheral B cell subsets, we and others have previously identified MZB1 (also referred to as pERp1 and PACAP) as an ER protein that is abundantly expressed in innate-like B cells and antibody-secreting cells (Bonfoco et al. 2001; Shimizu et al. 2009; van Anken et al. 2009; Flach et al. 2010). As the terms pERp1 and PACAP are used for unrelated genes and Mzb1 is approved by the Human Genome Organization (HUGO), we use $M z b 1$ throughout the text. Previous Mzb1 knockdown in MZ B cells or plasmacytoma cells revealed defects in antibody secretion, calcium signaling, and integrin-mediated adhesion (Shimizu et al. 2009; van Anken et al. 2009; Flach et al. 2010). In addition, cross-linking experiments indicated that MZB1 protein associates with the BiP and GRP94 chaperones and interacts with IgM in plasmacytoma cells (Shimizu et al. 2009; van Anken et al. 2009; Flach et al. 2010). However, the role of $\mathrm{MZB1}$ in vivo has been obscure.

Here, we examine the in vivo function of MZB1 by conditional gene inactivation in the mouse germline as well as early and late stages of B-cell differentiation. We found that MZB1 is required for efficient humoral immune responses to T-cell-independent and T-cell-dependent (TD) antigens. In addition, we show that tunicamycin or Cre-induced genotoxic stress synergizes with MZB1 deficiency to generate a developmental block at the transition of pro-B to pre-B cells. Finally, MZB1 interacts directly with the chaperone GRP94 in an ATP-sensitive manner and is required for the association of GRP94 with its substrate, $\mu \mathrm{HC}$, under conditions of ER stress.

\section{Results}

Impaired humoral immune responses in Mzb1deficient mice

Previous knockdown experiments implicated MZB1 in the secretion of antibodies in plasmacytoma cells and lipopolysaccharide (LPS)-stimulated FoB cells (Shimizu et al. 2009; van Anken et al. 2009; Flach et al. 2010). To investigate the functional role of MZB1 in vivo, we generated mice carrying a mutant allele of $M z b 1$ in which exons 2-4 are flanked by lox $P$ sites, and a splice acceptor site and EGFP reporter are inserted downstream from the 3' $\operatorname{lox} P$ site (Supplemental Fig. S1A; Eferl et al. 2004). Successful homologous recombination of the targeting construct in embryonic stem (ES) cells was confirmed by DNA blot and PCR analysis, including the cloning and sequencing of the amplified locus (Supplemental Fig. S1B; data not shown). Upon germline transmission, the neomycin selection cassette was deleted by crossing $M z b 1^{+/ f l ; n e o}$ mice with mice expressing the FLPe recombinase under the control of the human actin promoter (Rodriguez et al. 2000). We crossed $M z b 1^{f l}$ mice with a $C M V$-cre transgenic strain that deletes loxP-flanked gene segments in germ cells (Schwenk et al. 1995). Successful gene ablation was confirmed by PCR analysis (Supplemental Fig. S1C). The $C M V$-cre allele was subsequently crossed out to generate $M z b 1^{-/-}$mice.

Flow cytometric analysis of $M z b 1^{-/-}$splenocytes revealed normal frequencies of $\mathrm{CD} 9^{+} \mathrm{B}$ cells, including $\mathrm{CD} 19^{+} \mathrm{AA} 4.1^{+}$immature $\mathrm{B}$ cells, as well as $\mathrm{CD} 21^{\text {int }} \mathrm{CD} 23^{+}$ FoB and CD21 ${ }^{\text {hi CD23 }}{ }^{-}$MZ B cells (Fig. 1A; Supplemental Fig. S1D). $M z b 1^{-/-}$mice also showed normal frequencies of peritoneal B-1a and $\mathrm{B}-1 \mathrm{~b}$ cells as well as normal $\mathrm{B} 220^{+} \mathrm{CD}_{4} 3^{+}$pro-B-cell and $\mathrm{B} 220^{\text {int }} \mathrm{CD} 43^{-}$pre-B-cell compartments in the bone marrow (Fig. 1B,C; Supplemental Fig. S1E). Moreover, competitive bone marrow reconstitution experiments in which we transferred equal numbers of CD45.1 $1^{+}$wild-type and CD45.2 $\mathrm{Mzb}^{-/-}$bone marrow cells into $\mathrm{Rag}^{-/-} \mathrm{Il} 2 \mathrm{rg}^{-/-}$mice revealed similar proportions of wild-type and mutant splenic B cells (Supplemental Fig. S1F,G).

As previous Mzb1 knockdown experiments in LPSstimulated MZ B cells implicated MZB1 in antibody secretion (Flach et al. 2010), we examined the surface expression of IgM and humoral immune responses in $M z b 1^{-1-}$ mice. Similar IgM surface expression was detected by flow cytometry in $\mathrm{MZ} \mathrm{B}$ and $\mathrm{FoB}$ cells of $\mathrm{Mzb1}^{+/+}$and $M z b 1^{-/-}$mice (Fig. $1 \mathrm{D}$; data not shown). MZ $B$ cells are able to initiate TD antigen responses (Constant et al. 1995; Attanavanich and Kearney 2004) and are crucial for an early plasmablast response to blood-borne T-cell-independent type 2 (TI-2) antigens, such as bacterial polysaccharides (Martin et al. 2001). Therefore, we intravenously challenged $\mathrm{Mzb1}^{+/+}$and $\mathrm{Mzb1}^{-/-}$mice with the TI-2 antigen TNP-Ficoll or Streptococcus pneumoniae type 3 polysaccharide (S.p. PS) Rijkers and Mosier 1985; Bruyn et al. 1992) and monitored the increase of hapten-specific antibodies over time. Antigen-specific IgM antibody titers increased between day 2 and day 4; 
A

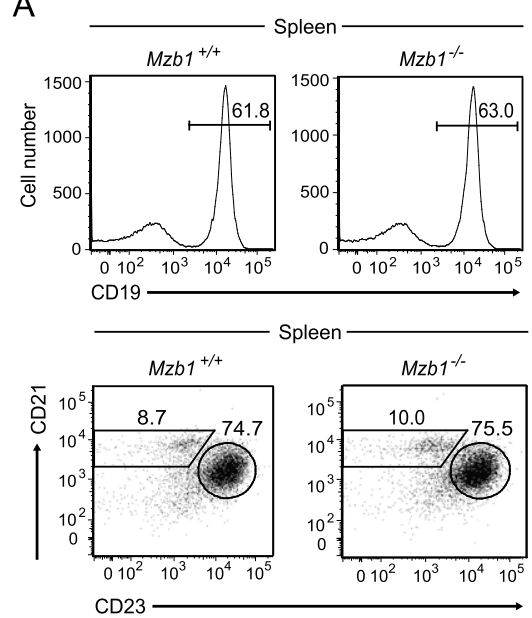

D
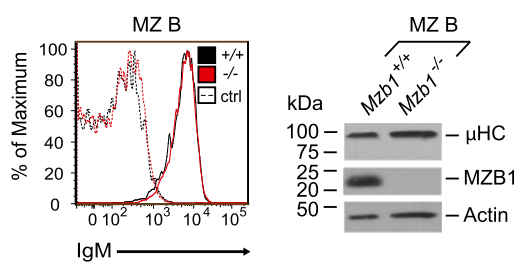

F

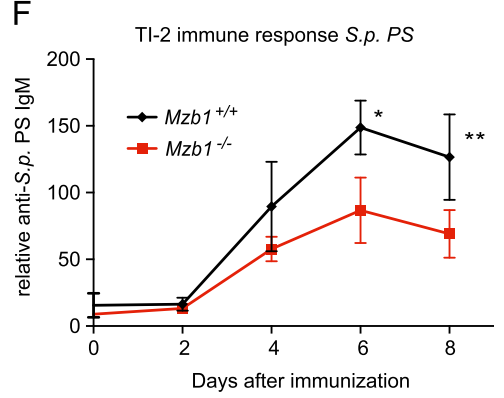

B

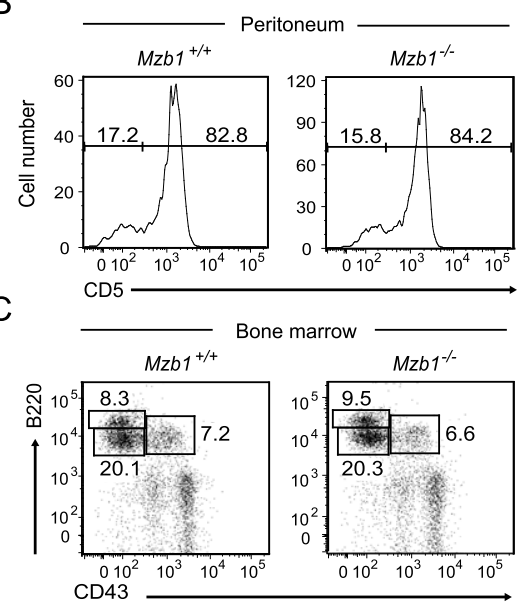

E

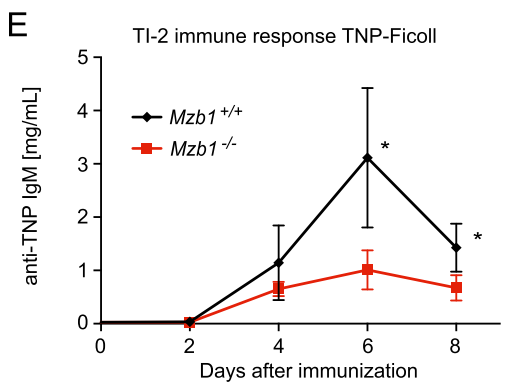

G

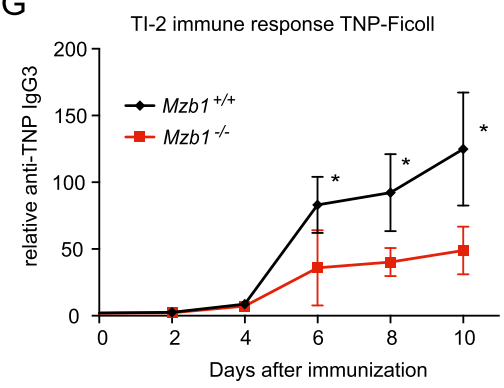

Figure 1. Impaired T-cell-independent immune responses in Mzb1-deficient mice. $(A$, top panel) Flow cytometric analysis of the splenic cell compartment in $\mathrm{Mzb1}^{+/+}$and $M z b 1^{-1-}$ mice to detect $\mathrm{CD} 19^{+} \mathrm{B}$ cells within the living lymphocyte gate. (Bottom panel) Mature $\mathrm{CD} 19^{+} \mathrm{AA} 4.1^{-}$cells are further gated into $\mathrm{CD} 21^{\text {int }} \mathrm{CD} 23^{+} \mathrm{FoB}$ and $\mathrm{CD} 21^{\mathrm{hi}} \mathrm{CD} 23^{-}$ MZ B cells. (B) FACS profile of $\mathrm{Mzb1}^{+/+}$and $M z b 1^{-1-}$ peritoneal CD $19^{+} \mathrm{CD} 23^{-} \mathrm{B}-1 \mathrm{~B}$ cells that are gated into the $\mathrm{CD} 5^{+} \mathrm{B}-1 \mathrm{a}$ and $\mathrm{CD} 5^{-}$ B-1b population. $(C)$ Flow cytometric profile of $\mathrm{Mzb1}^{+/+}$and $\mathrm{Mzb1}^{-/-}$living bone marrow cells to detect $\mathrm{B} 22 \mathrm{O}^{+} \mathrm{CD} 43^{+}$pro-B and early pre- $\mathrm{B}$ cells, $\mathrm{B} 220^{\text {int }} \mathrm{CD} 43^{-}$late pre- $\mathrm{B}$ and immature $\mathrm{B}$ cells, and $\mathrm{B} 220^{\text {hi }} \mathrm{CD} 43^{-}$recirculating B cells. Numbers indicate the percentage of cells within the gated population. The data shown in $A-C$ are representative of five or more experiments. $(D$, left panel) Flow cytometric analysis of $\mathrm{Mzb1}^{+/+}$(black line) and $\mathrm{Mzb1}^{-1-}$ (red line) mice to detect surface expression of IgM on gated MZ B cells. Dashed lines represent the isotype control for each indicated genotype. Data are representative of three independent experiments comprising four animals of each genotype. (Right panel) Immunoblot analysis of sorted MZ B cells to detect cellular expression of $\mu \mathrm{HC}$ and MZB1. Actin served as a loading control. The immunoblot shown is representative of four independent experiments. $(E-G)$ TI-2 immune response to $25 \mu \mathrm{g}$ of intravenously injected TNP-Ficoll $(E, G)$ and $0.5 \mu \mathrm{g}$ of S.p. PS $(F)$ in $\mathrm{Mzb1}^{+/+}(n=4$; black line $)$ and $M z b 1^{-1-}(n=4$; red line) mice in a 129S2/SvPas background. TNP-specific IgM $(E)$ and IgG3 $(G)$ as well as anti-S.p. PS-specific $\operatorname{IgM}(F)$ antibodies in prepared blood serum at the indicated time points were detected with an ELISA. Data points indicate the mean of the serum titers of analyzed mice, whereas the error bars represent the standard deviation (SD) of the mean. Statistical difference between the means of individual time points was analyzed by an unpaired two-tailed Student's $t$-test. $\left({ }^{\star}\right) P \leq 0.05 ;\left(^{\star \star}\right) P \leq 0.005$. Data in $E-G$ are representative of two independent experiments.

however, the immune response of $\mathrm{Mzb1}^{-/-}$mice was significantly reduced compared with $\mathrm{Mzb1}^{+/+}$mice (Fig. $1 \mathrm{E}, \mathrm{F})$. MZ B cells also generate significant levels of IgG3 during a TI-2 response (Guinamard et al. 2000; Zheng et al. 2013) and are capable of switching to IgG3 upon in vitro stimulation with LPS and IL-4 (Oliver et al. 1997). Indeed, we detected reduced amounts of anti-TNP-specific antibodies of the IgG3 isotype in $M z b 1^{-/-}$mice compared with $\mathrm{Mzb1}^{+/+}$mice throughout the TI-2 response (Fig. 1G).

To examine whether the impaired humoral immune response in $\mathrm{Mzb1}^{-/-}$mice is due to a B-cell-intrinsic defect, we crossed $M z b 1^{f l / f 1}$ mice with the CD21-cre transgenic strain in which the Cre recombinase gene is expressed in transitional and mature B-cell stages in the spleen (Kraus et al. 2004). Consistent with the expression of CD21-cre, MZB1 protein levels were found to be decreased at the $\mathrm{CD} 19^{+} \mathrm{AA} 4.1^{+} \mathrm{IgM}^{\mathrm{hi}} \mathrm{CD} 23^{-}$transitional 1 (T1) B-cell stage, and MZB1 was undetectable in mature FoB and MZ B cells (Fig. 2A). Flow cytometric analysis showed normal numbers of splenic B cells in $M z b 1^{f l / f 1} C D 21$-cre mice (Supplemental Fig. S2A). Moreover, we detected normal frequencies of transitional B cells (type 2 and 3 ), FoB cells, and MZ B cells (Fig. 2B,C). In FoB and MZ B cells of Mzb1 $1^{f / f l} \mathrm{CD} 21$-cre mice, we also observed virtually normal levels of surface IgM (Fig. 2D).

Immunization of $M z b 1^{f l / f l} C D 21$-cre mice and $\mathrm{Mzb1}^{+/+}$ CD21-cre control mice with the TD antigen TNP-KLH revealed a significantly reduced anti-TNP-specific immune response of the IgM isotype in $\mathrm{Mzb}^{-f l f l} \mathrm{CD} 21$-cre mice (Fig. 2E). In $M z b 1^{f l / f l} C D 21$-cre mice immunized with the TI-2 antigen TNP-Ficoll, TNP-specific IgM antibody titers were not detected until day 6 and decreased afterward, whereas in $\mathrm{Mzb1}^{+/+} \mathrm{CD} 21$-cre mice, the corresponding antibody titers increased between day 2 and day 4 and 
A

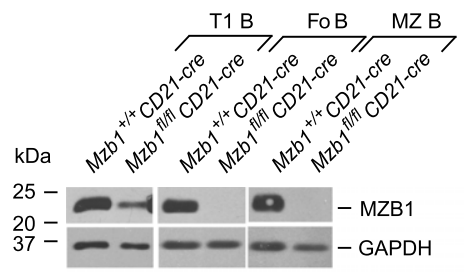

C

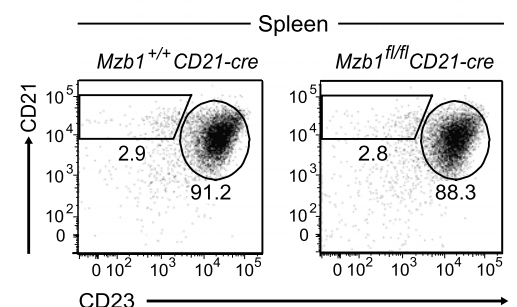

$E$

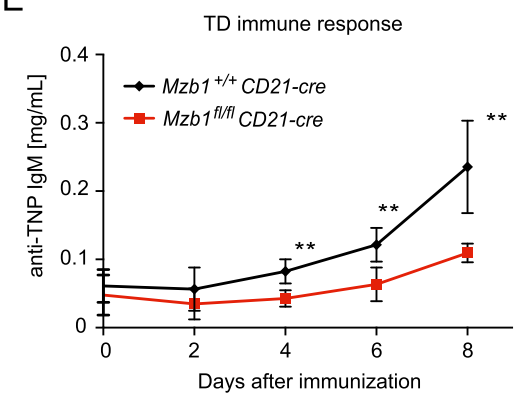

G

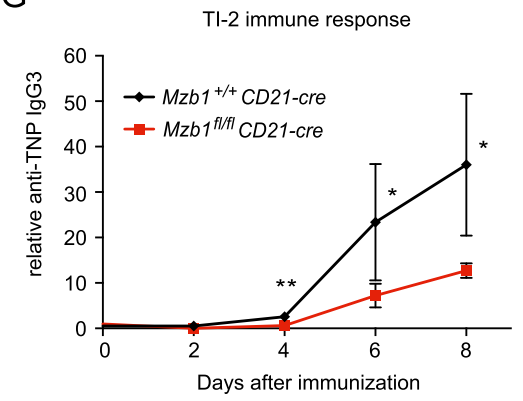

B

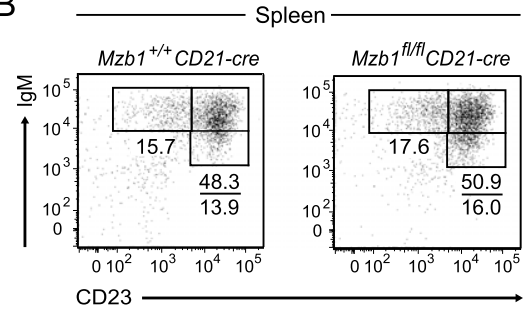

D

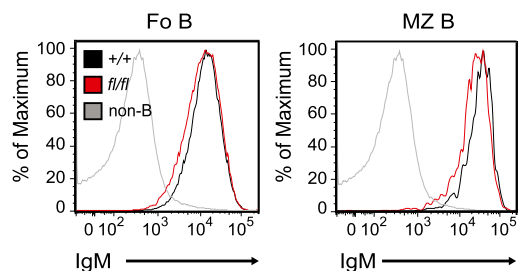

$\mathrm{F}$

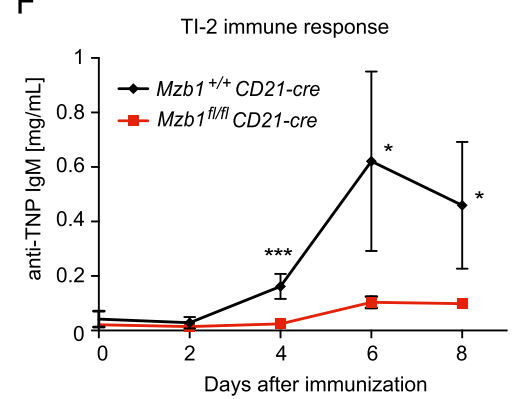

$\mathrm{H}$

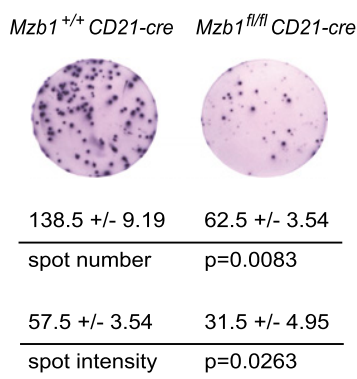

Figure 2. Defects in humoral immune responses of $M z b 1^{f l / f l} C D 21$-cre mice. (A) Immunoblot analysis of sorted immature $\mathrm{CD} 19^{+} \mathrm{AA} 4.1^{+} \mathrm{IgM}^{\mathrm{hi}} \mathrm{CD} 23^{-}$transitional $\mathrm{T} 1 \mathrm{~B}$ cells, mature $\mathrm{CD} 19^{+} \mathrm{AA} 4.1^{-} \mathrm{CD} 21^{\text {int }} \mathrm{CD} 23^{+}$ FoB cells, and $\mathrm{CD} 19^{+} \mathrm{AA} 4.1^{-} \mathrm{CD} 21^{\mathrm{hi}} \mathrm{CD} 23^{-}$ $\mathrm{MZ} B$ cells of the indicated genotypes to examine the expression level of MZB1. GAPDH served as a loading control. Data are representative of two biological replicates each. $(B)$ Flow cytometric analysis of splenic CD19+AA4. $1^{+}$ immature B-cell stages gated for $\mathrm{IgM}^{\mathrm{hi}} \mathrm{CD} 23^{-}$ $\mathrm{T} 1, \operatorname{IgM}^{\mathrm{hi}} \mathrm{CD} 23^{+} \mathrm{T} 2$, and $\operatorname{IgM}^{\mathrm{lo}} \mathrm{CD} 23^{+} \mathrm{T} 3 \mathrm{~B}$ cells. (C) FACS profile of splenic $\mathrm{CD} 19^{+} \mathrm{AA} 41^{-}$ gated mature $B$ cells to detect the percentage of FoB and MZ B cells. Numbers in quadrants indicate the percentage of cells within the gated population. Data in $B$ and $C$ are representative of five or more experiments. (D) Flow cytometric analysis of $\mathrm{Mzb1}^{+/+} \mathrm{CD} 21$-cre (black line) and $M z b 1^{f l / f l} C D 21-c r e$ (red line) mice to detect IgM surface expression on gated FoB and MZ B cells. As a control, $\mathrm{CD} 19^{-}$non-B cells (gray line) were gated for IgM expression. Data are representative of three or more experiments. $(E, F)$ Primary immune responses to the TD antigen TNP-KLH $(E)$ and TI-2 antigen TNPFicoll $(F)$. Following intraperitoneal injection of $150 \mu \mathrm{g}$ of adsorbed TNP-KLH or intravenous injection of $25 \mu \mathrm{g}$ of TNP-Ficoll, blood serum of $M z b 1^{+/+} C D 21$-cre mice $(n=8 ; n=5$; black lines) and $M z b 1^{f l / f 1} C D 21$-cre mice $(n=4 ; n=4$; red lines) was analyzed by ELISA for the presence of anti-TNP IgM antibodies at the indicated time points. Each data point represents the mean of the respective cohort, whereas error bars indicate the SD of the mean. An unpaired two-tailed Student's $t$-test was employed for statistical analysis of individual time points. $\left(^{\star}\right) P \leq 0.05$; $\left(^{\star \star}\right) P \leq 0.005$; $\left({ }^{\star \star \star}\right) P \leq 0.001$. $(G)$ Analysis of IgG3 serum titers of $M z b 1^{+/+} C D 21$-cre $(n=4$; black line) and $M z b 1^{f l / f l} C D 21$-cre $(n=4$; red line) mice injected with $25 \mu \mathrm{g}$ of TNP-Ficoll. Serum was collected on the indicated days and analyzed by an ELISA to detect anti-TNP antibodies of the IgG3 isotype in comparison with a reference sample. $\left({ }^{\star}\right) P \leq 0.05$; $\left(^{\star \star}\right) P \leq 0.005$. $(H)$ ELISpot assay of B220 ${ }^{\text {lo }} \mathrm{CD} 138^{+}$plasma cells sorted $5 \mathrm{~d}$ post-immunization with intravenously administered NP-Ficoll to detect NP-specific IgM-secreting cells and their secretion efficiency. Data indicate the mean and SD of triplicates. Statistical differences in the number of antibody-secreting cells and the spot intensity were assessed with an unpaired two-tailed Student's $t$-test. Data are representative of three biological replicates of each genotype.

peaked at day 6 (Fig. 2F). Moreover, the amount of antiTNP-specific antibodies of the IgG3 isotype was found to be reduced in $M z b 1^{f l / f l} C D 21$-cre mice (Fig. 2G; Supplemental Fig. S2B).

The impaired immune response could be ascribed to impaired plasma cell differentiation and/or altered efficiency of antibody secretion. To this end, we analyzed the frequency of $\mathrm{B} 220^{\mathrm{lo}} \mathrm{CD} 138^{+}$plasma cells post-immunization and determined antibody secretion by ELISpot analysis. The percentage of plasma cells was not significantly altered in Mzb1-deficient mice (Supplemental Fig. S2C). However, the number of antibody-secreting cells within the plasma cell population and the amount of secreted antibody per cell, as determined by the number and intensity of spots, were approximately twofold reduced relative to wild-type controls (Fig. $2 \mathrm{H}$; Supplemental Fig. S2D). In addition, we examined the amount of secreted IgM of LPS-stimulated MZ B cells and observed that the secreted IgM titers were approximately twofold reduced relative to the $\mathrm{Mzb1}^{+/+} \mathrm{CD} 21$-cre control (Supplemental Fig. S2E). Since LPS is sensed through Toll-like receptor 4 (TLR4), which subsequently initiates a signaling cascade resulting in B-cell activation and differentiation toward the plasma cell stage, we determined the cell surface 
expression level of TLR4. Neither TLR4 nor the B-cell activation marker CD86 was affected by the absence of MZB1 (Supplemental Fig. S2F,G). Therefore, the inactivation of $M z b 1$ in immature B cells reduces humoral immune responses by affecting the number of antibody-secreting plasma cells and the efficiency of antibody secretion.

\section{Pharmacologically induced ER stress synergizes with the Mzb1-null mutation}

The normal surface $\operatorname{IgM}$ expression in unstimulated mature B cells raises the questions of whether MZB1 is only required for secretion of IgM and whether naturally occurring ER stress in antibody-secreting cells augments the requirement for MZB1. To this end, we intraperitoneally administered the UPR inducer tunicamycin in $\mathrm{Mzb1}^{-/-}$and $\mathrm{Mzb1^{+/+ }}$ littermates and analyzed the B-cell populations in the bone marrow and spleen. We could not detect any difference in the frequency of mature splenic B cells between tunicamycin-treated $\mathrm{Mzb1}^{-/-}$and $\mathrm{Mzb1}^{+/+}$ mice (data not shown). However, in the bone marrow of tunicamycin-treated $M z b 1^{-/-}$mice, we observed a signif- icant reduction in the $\mathrm{B} 220^{\text {int }} \mathrm{CD} 43^{-}$pre-B-cell compartment relative to tunicamycin-treated $\mathrm{Mzb1}^{+/+}$mice (Fig. 3A,B). Moreover, in tunicamycin-treated $\mathrm{Mzb1}^{-/-}$mice, the percentage of $\mathrm{B} 22 \mathrm{O}^{+} \mathrm{CD} 43^{+}$pro-B cells was increased, indicative of a block in pro-B-cell to pre-B-cell differentiation. In contrast, the frequency of $\mathrm{B} 220^{\text {hi }} \mathrm{CD} 43^{-}$recirculating B cells was similar in tunicamycin-treated $M z b 1^{-/-}$ and $\mathrm{Mzb1}^{+/+}$mice (Fig. 3A). Semiquantitative RT-PCR analysis of mRNA of sorted pro-B cells, pre-B cells, and recirculating $\mathrm{B}$ cells for the presence of $X b p 1$ transcripts revealed a prominent $X b p 1 s$ band in $\mathrm{B} 220^{+} \mathrm{CD} 43^{+}$pro-B cells of vehicle-treated $M z b 1^{+/+}$and $M z b 1^{-/-}$mice (Fig. $3 C)$. However, the ratio of $X b p 1 s$ to the total amount of $X b p 1$ was further increased in tunicamycin-treated mice, and the highest ratio of $X b p 1 s$ to total $X b p 1$ was detected in pro-B cells of tunicamycin-treated $M z b 1^{-1-}$ mice (Fig. 3C, D). In pro-B cells of $M z b 1^{-1-}$ mice, we also detected an increased expression of the UPR-induced gene Ddit3 (Chop), which has been implicated in ER stress-induced cell death (Fig. 3E; Zinszner et al. 1998; Han et al. 2013). Tunicamycin treatment augmented the expression of Ddit3 in $M z b 1^{-/-}$pro-B cells, suggesting that the combination of
A

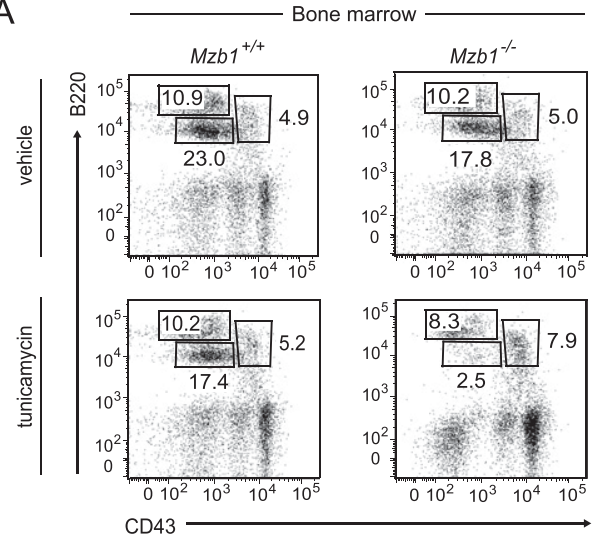

C

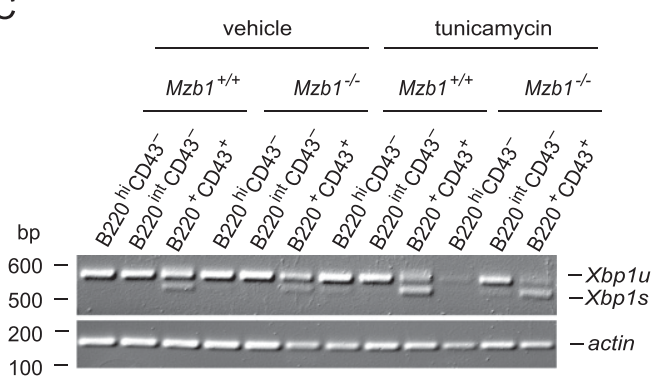

E

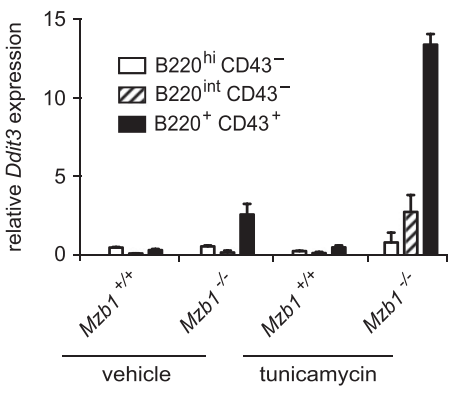

D

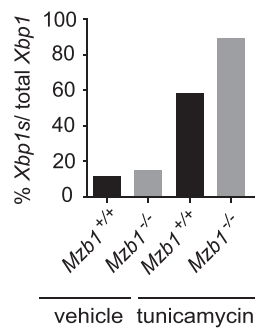

B

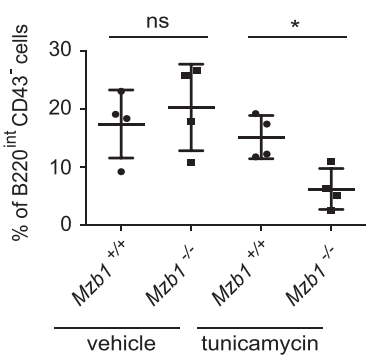

vehicle tunicamycin

Figure 3. Pharmacologically induced ER stress synergizes with the Mzb1-null mutation. $(A)$ Flow cytometric analysis of $\mathrm{Mzb1}^{+/+}$and $\mathrm{Mzb1^{-/- }}$ mice treated for $12 \mathrm{~h}$ with $150 \mathrm{mM}$ glucose (vehicle) or $10 \mu \mathrm{g}$ of tunicamycin per gram of body weight in $150 \mathrm{mM}$ glucose. Bone marrow cells of sacrificed mice were analyzed for the frequencies of $\mathrm{B} 220^{+} \mathrm{CD} 43^{+}$pro-B and early pre-B cells, $\mathrm{B} 220^{\text {int }} \mathrm{CD} 43^{-}$late pre-B and immature $\mathrm{B}$ cells, and $\mathrm{B} 220^{\text {hi }} \mathrm{CD} 43^{-}$recirculating $\mathrm{B}$ cells within the living lymphocyte gate. Numbers in quadrants indicate the percentage of cells. Data are representative of four experiments. $(B)$ Statistical analysis of the frequency of $\mathrm{B} 220^{\text {int }} \mathrm{CD} 43^{-}$pre- $\mathrm{B}$ cells of the indicated genotypes. A significant difference in the percentage of pre-B cells between $\mathrm{Mzb1}^{+/+}$and $\mathrm{Mzb1^{-1- }}$ mice was assessed by an unpaired two-tailed Student's $t$-test. $\left({ }^{\star}\right) P \leq$ 0.05; (ns) not significant. (C) Semiquantitative RT-PCR to detect the transcript levels of unspliced Xbp1 (Xbp1u) and Xbp1s in the indicated sorted B-cell populations shown in A. Actin served as a loading control. (D) Quantification of the amount of $X b p 1 s$ to the total amount of $X b p 1$ in the sorted $\mathrm{B} 220^{+} \mathrm{CD} 43^{+}$pro-B-cell compartment of vehicle- and tunicamycin-treated $\mathrm{Mzb1}^{+/+}$and $M z b 1^{-1-}$ mice using ImageJ. (E) Quantitative RTPCR of the indicated sorted cell populations shown in $A$ of vehicle- or tunicamycin-treated $\mathrm{Mzb1}^{+/+}$ and $\mathrm{Mzb1}^{-1-}$ mice to detect the mRNA expression level of the UPR-induced gene Ddit3, normalized to the transcript levels of Actin. Error bars indicate the SD of the mean of technical triplicates. Data in $C$ and $E$ are representative of three independent experiments. 
Mzb1 deficiency and UPR-mediated ER stress results in a block of pro-B-cell to pre-B-cell differentiation.

$M Z B 1$ is required for the interaction of $\mu \mathrm{HC}$ with GRP94 under conditions of ER stress

Previous reports indicated that MZB1 is coimmunoprecipitated with $\mu \mathrm{HC}$ in lysates of cross-linked plasmacytoma cells (Shimizu et al. 2009; van Anken et al. 2009). We confirmed an association of MZB1 with $\mu \mathrm{HC}$ in lysates of cross-linked B1-8 plasmacytoma cells (data not shown).
However, in lysates of non-cross-linked B1-8 cells, the interaction between MZB1 and $\mu \mathrm{HC}$ is virtually undetectable and can be detected only upon treatment of cells with tunicamycin (Fig. 4A). Moreover, the association of MZB1 with the chaperone GRP94 could be detected only under conditions of tunicamycin-induced ER stress, which results in an up-regulation of GRP94 (Fig. 4B).

GRP94 is a substrate-specific chaperone implicated in the folding of secreted IgM (Melnick et al. 1994). Therefore, we examined whether the interaction of MZB1 with
A

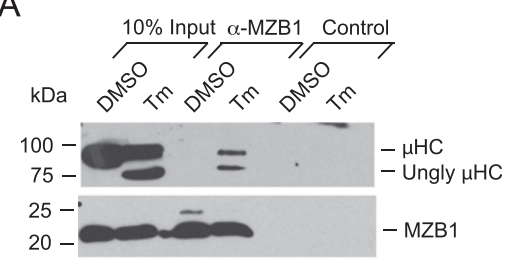

C

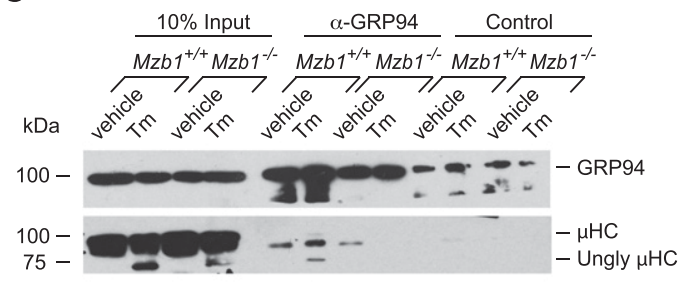

B
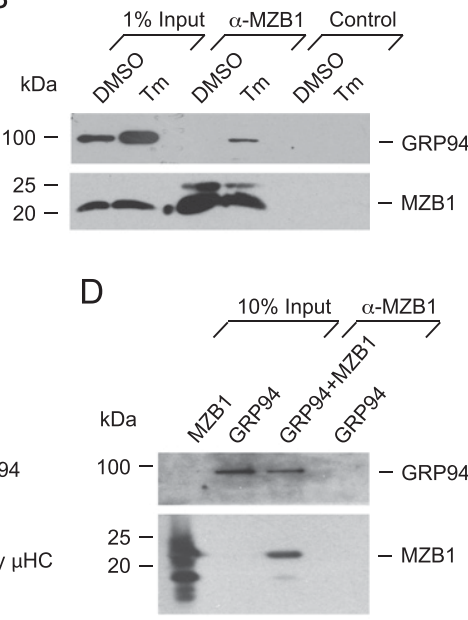

$E$

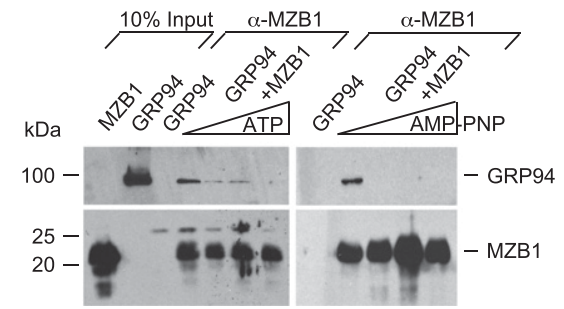

G

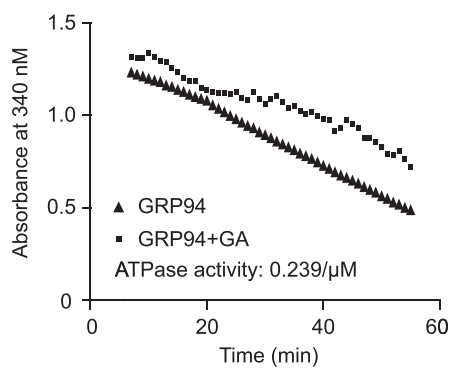

$\mathrm{F}$

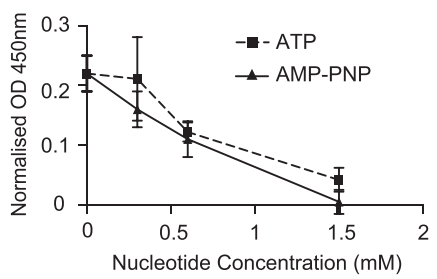

$\mathrm{H}$

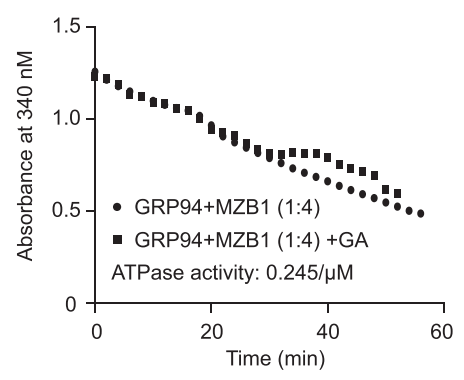

Figure 4. $\mathrm{MZB} 1$ is required for the interaction of $\mu \mathrm{HCs}$ with GRP94 under ER stress. $(A, B)$ Co-IP approach using a monoclonal MZB1-specific antibody or anti-rat IgG2a isotype control cross-linked to sepharose beads to detect the association of MZB1 with $\mu \mathrm{HCs}(A)$ and GRP94 $(B)$ in non-cross-linked B1-8 plasmacytoma cells. Cells were treated with the diluent DMSO or $5 \mu \mathrm{g} / \mathrm{mL}$ tunicamycin $(\mathrm{Tm})$ for $8 \mathrm{~h}$. Data are representative of three or more experiments. (Ungly) Unglycosylated. $(C)$ Co-IP approach to detect the interaction of GRP94 with $\mu \mathrm{HCs}$ in MACSsorted CD $19^{+}$splenic B cells of $M z b 1^{-/-}$and $\mathrm{Mzb}^{+/+}$mice that had been treated with 150 $\mathrm{mM}$ glucose (vehicle) or $10 \mu \mathrm{g}$ of tunicamycin per gram of body weight in $150 \mathrm{mM}$ glucose for $12 \mathrm{~h}$. Immunoprecipitation of GRP94 from cell lysates was performed using a GRP94-specific polyclonal antibody or an isotype control. GRP94-associated $\mu \mathrm{HCs}$ were subsequently detected with a $\mu \mathrm{HC}$ specific antibody. Data are representative of three experiments. (D) Co-IP approach of recombinant MZB1 and purified mouse liver GRP94 to detect a direct interaction of MZB1 and GRP94. Recombinant MZB1 was incubated with murine GRP94 and purified by an anti-MZB1 monoclonal antibody coupled to sepharose beads. MZB1-associated GRP94 was subsequently detected with a GRP94-specific polyclonal antibody. As a control, GRP94 was incubated with antiMZB1 coupled to sepharose beads. Data are representative of three experiments. $(E)$ CoIP approach to detect the association of purified mouse liver GRP94 and recombinant MZB1 in the presence of increasing concentrations $(0,0.25,0.5$, and $1 \mathrm{mM})$ of the nucleotide ATP (left panel) or its nonhydrolyzable analog, AMP-PNP (right panel). Immunopurification of recombinant MZB1 was performed with an anti-MZB1 antibody

coupled to sepharose beads, and copurified GRP94 was detected with a GRP94-specific polyclonal antibody. A reaction of GRP94 and anti-MZB1 coupled to sepharose beads served as a control. Data are representative of two experiments. (F) ELISA-based assay to detect the interaction between GRP94 and MZB1. Recombinant MBP-GRP94 or MPB as a control was immobilized on an ELISA plate and incubated with recombinant MZB1 in the presence of increasing concentrations of ATP or its nonhydrolyzable form, AMP-PNP, in triplicates. GRP94-associated MZB1 was detected by a rat anti-MZB1 monoclonal antibody followed by an anti-rat HRP detection step. $\mathrm{OD}_{450}$ readings were normalized to background MBP values; each data point indicates the mean and the SD of the triplicates. Data are representative of four independent experiments. $(G, H)$ Enzymatic assay to detect the ATPase activity of GRP94 in the absence $(G)$ and presence $(H)$ of a fourfold molar excess of recombinant MZB1. A reaction with geldanamycin (GA), which specifically blocks the ATPase activity of GRP94, was used to assess any residual contaminating background ATPase activity. The slope of the graph represents the actual ATPase activity. 
GRP94 and/or $\mu \mathrm{HC}$ is important for binding of GRP94 to $\mu \mathrm{HC}$ in vivo. To this end, we performed coimmunoprecipitation (co-IP) experiments with lysates of splenic B cells that were sorted from vehicle-treated and tunicamycintreated $\mathrm{Mzb1}^{-/-}$and $\mathrm{Mzb1}^{+/+}$mice. In B cells from vehicle-treated $M z b 1^{-/-}$and $M z b 1^{+/+}$mice, we detected an association of GRP94 with the $\mu \mathrm{HC}$ (Fig. 4C). However, this GRP94: $\mu \mathrm{HC}$ association was undetectable in B cells from tunicamycin-treated $M z b 1^{-/-}$mice, although it was even increased in cells from tunicamycin-treated $M z b 1^{+/+}$mice.

MZB1 shows homology with the Canopy family of proteins, including six conserved cysteines and the C-terminal ER retrieval signal (data not shown). One of the four members of this protein family, CNPY3 (PRAT4A), has been shown to function as a cochaperone of GRP94 in the folding process of TLR4 (Liu et al. 2010). Cochaperones interact directly with the chaperones, and therefore we examined the interaction of purified GRP94 and recombinant MZB1 by an in vitro immunopurification assay. MZB1 was able to directly associate with the chaperone GRP94 (Fig. 4D). The binding of MZB1 to GRP94 was sensitive to increasing concentrations of ATP (Fig. 4E,F), which is reminiscent of the ATP sensitivity of the interaction of GRP94 with the TLR4specific cochaperone CNPY3 (Liu et al. 2010). However, ATP hydrolysis is not required for abolishing the observed interaction, as the association of MZB1 and GRP94 could also be prevented in a dose-dependent manner by the nonhydrolyzable ATP analog AMP-PNP (Fig. 4E,F). Despite the competitive binding of MZB1 and ATP to the chaperone GRP94, we could not observe any obvious difference in the ATPase activity of GRP94 in the absence and presence of MZB1 (Fig. 4G,H). Thus, MZB1 potentiates the interaction of $\mu \mathrm{HC}$ with the substrate-specific chaperone GRP94 under conditions of UPR-induced ER stress and shares properties with another GRP94 cochaperone.

$M b 1^{C r e}$-induced genotoxic stress unmasks a role for $M Z B 1$ in pro- $B$ cells

Tunicamycin treatment of mice unmasked a specific role for MZB1 in pro-B-cell to pre-B-cell differentiation. In these experiments, we detected $X b p 1 s$ expression already in untreated $\mathrm{B} 22 \mathrm{O}^{+} \mathrm{CD} 43^{+}$pro-B cells but not in $\mathrm{B} 220^{\text {hi }} \mathrm{CD} 43^{-}$ recirculating mature $\mathrm{B}$ cells (Fig. $3 \mathrm{C}$ ). The UPR detected in untreated wild-type pro-B and pre-B cells may be linked to genotoxic stress by RAG-mediated recombinations of the Ig loci. Genotoxic stress can also be induced by expression of Cre recombinase (Loonstra et al. 2001; Pfeifer et al. 2001).

Analysis of $M z b 1^{f l / f 1} m b 1^{C r e}$ mice in which the $M z b 1$ allele was deleted by the expression of a codon-optimized Cre recombinase in pro-B cells (Supplemental Fig. S3A,B; Hobeika et al. 2006) indicated a reduced size of the spleens of $M z b 1^{f l / f l} m b 1^{C r e}$ mice relative to $M z b 1^{+/+} m b 1^{C r e}$ control mice (Supplemental Fig. S3C). Flow cytometric analysis of the splenic B-cell compartment showed a marked decrease in the number of $\mathrm{CD}^{+} 9^{+} \mathrm{B}$ cells (Fig. 5A).
Moreover, the frequency of peritoneal B cells was reduced in $M z b 1^{f l / f 1} m b 1^{C r e}$ mice (Supplemental Fig. S3D). Flow cytometric analysis of the bone marrow of $M z b 1^{f l / f l} m b 1^{\text {Cre }}$ and $M z b 1^{+/+} m b 1^{C r e}$ mice indicated that Mzb1-deficient B-lineage cells did not efficiently differentiate beyond the B220 ${ }^{+} \mathrm{CD}_{4} 3^{+}$pro-B-cell stage (Fig. 5B). Consistent with the block at the transition from pro-B to pre-B cells, $M z b 1^{f l / f l} m b 1^{C r e}$ mice showed a marked reduction in CD2 $5^{+}$pre-B cells and an increase in the percentage of B220 ${ }^{+} \mathrm{CD} 19^{+} \mu \mathrm{HC}^{-} \mathrm{CD} 25^{-}$late pro-B cells (Fig. $5 \mathrm{C}$ ). The pro-B-cell to pre-B-cell transition is characterized by the complete rearrangement of the Igh gene and the assembly and expression of the pre-BCR.

To address the question of whether the developmental block in $M z b 1^{f l / f I} m b 1^{C r e}$ mice can be rescued by the expression of a functionally rearranged $\mu \mathrm{HC}$, we crossed $M z b 1^{f l / f l} m b 1^{C r e}$ mice with $I g h^{B 1-8 / B 1-8} I g k^{-/-}$mice that carry a productively rearranged $I g h$ gene (Takeda et al. 1993; Sonoda et al. 1997). However, flow cytometric analysis of bone marrow cells of $M z b 1^{f l / f 1} \mathrm{mb1} 1^{C r e} I g h^{B 1-8}$ mice revealed that pro-B cells did not efficiently traverse to the $\mathrm{B} 220^{\text {int }} \mathrm{CD} 43^{-}$pre-B-cell stage (Fig. 5D). Thus, other mechanisms associated with the function of the pre-BCR may account for the developmental block in $M z b 1^{f l / f 1} m b 1^{C r e}$ mice.

The developmental block of $M z b 1^{f l / f 1} m b 1^{C r e}$ mice resembles that found in tunicamycin-treated $\mathrm{Mzb1}^{-/-}$mice and coincides with the stage at which the pre-BCR complex provides a signal for further differentiation to generate immature B cells (Kitamura et al. 1991, 1992). Therefore, we examined the surface expression of the preBCR by flow cytometry and found that the frequency of cells positive for both $\mu \mathrm{HC}$ and the Ig surrogate light chain $\lambda 5$ is reduced by a factor of three in $M z b 1^{f 1 / f 1} \mathrm{mb1} 1^{\text {Cre }}$ mice relative to $M z b 1^{+/+} m b 1^{C r e}$ mice (Fig. 5E,F). Cell surface expression of $\lambda 5$, which can be detected in wildtype pro-B cells even in the absence of $\mu \mathrm{HC}$ (Karasuyama et al. 1994; Winkler et al. 1995), appeared to be normal. Thus, the impaired surface expression of the pre-BCR may reflect a defect in the surface expression of $\mu \mathrm{HC}$. As the majority of pre-BCR complexes is retained in the intracellular compartment of the ER (Brouns et al. 1996; Mielenz et al. 2003), we crossed $M z b 1^{f l / f 1} m b 1^{\text {Cre }}$ mice onto a Slp $65^{-/-}$background in which the surface expression of the pre-BCR complex is increased due to impaired pre-BCR receptor down-regulation (Jumaa et al. 1999; Flemming et al. 2003). In the bone marrow of $M z b 1^{f 1 / f 1}$ $\mathrm{mb1} 1^{\mathrm{Cre}} \operatorname{Slp} 65^{-/-}$mice, the frequency of $\mu \mathrm{HC}^{+} \lambda 5^{+}$cells was reduced 2.5 -fold relative to $\mathrm{Mzb1^{+/+ }} \mathrm{mb1}{ }^{\mathrm{Cre}} \mathrm{Slp} 65^{-/-}$ littermate controls, whereas the percentage of cells expressing only $\lambda 5$ was increased (Supplemental Fig. S3E,F). Consistent with these findings, primary bone marrow-derived IL-7 B-cell cultures of $M z b 1^{f l / f 1} m b 1^{C r e}$ mice showed a marked decrease in the number of cells expressing surface $\mu \mathrm{HC}$, although the frequency of cells expressing intracellular $\mu \mathrm{HC}$ was similar to that found in $M z b 1^{+/+} m b 1^{C r e}$ IL-7 B-cell cultures (Fig. 5G,H). Both $M z b 1^{+/+} m b 1^{C r e}$ and $M z b 1^{f l / f l} m b 1^{C r e}$ cell cultures contained surface $\mu \mathrm{HC}$-positive cells that were also Igкpositive, as evidenced by anti- $\kappa$ staining and analysis of 
A

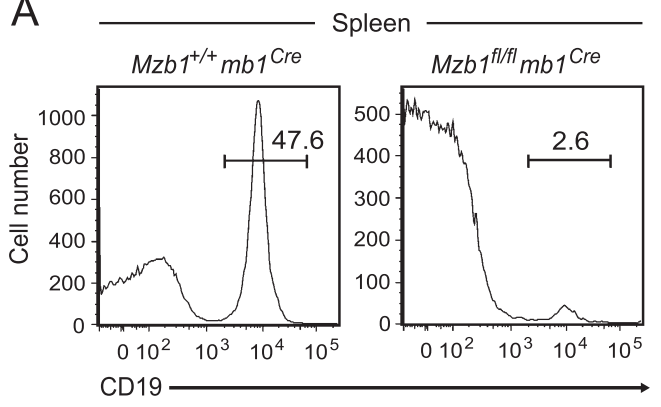

C

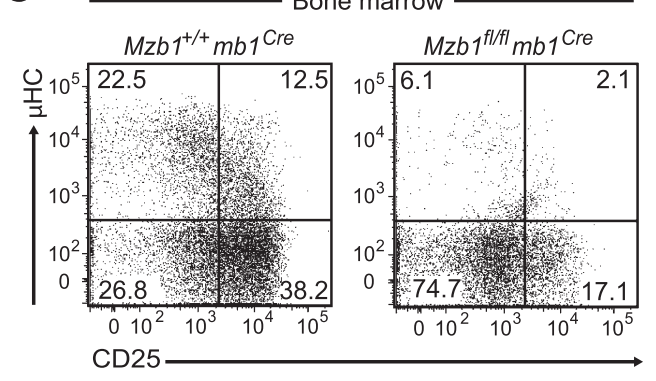

B

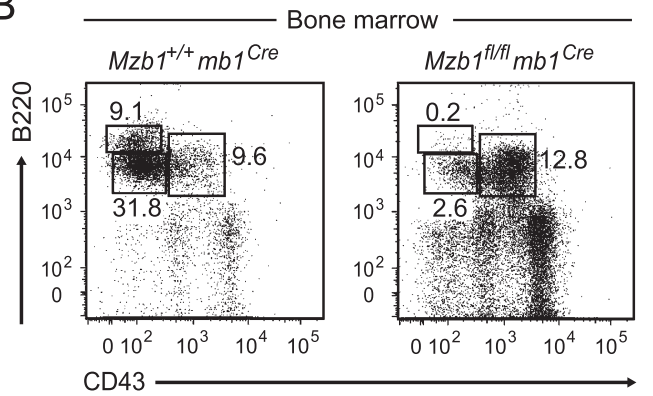

D

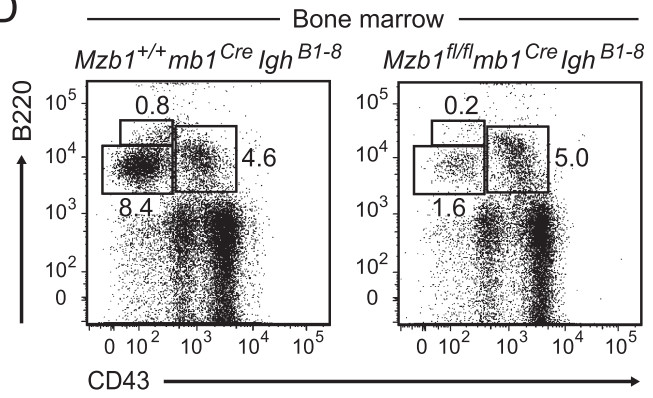

Streptavidin control

F

$\mathrm{Mzb1}^{+/+} \mathrm{mb1}{ }^{\mathrm{Cre}}$

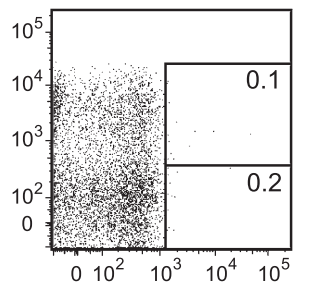

E
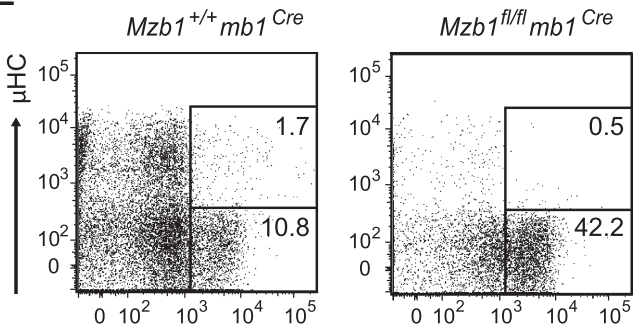

$\lambda 5$

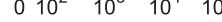

$\mathrm{H}$

G

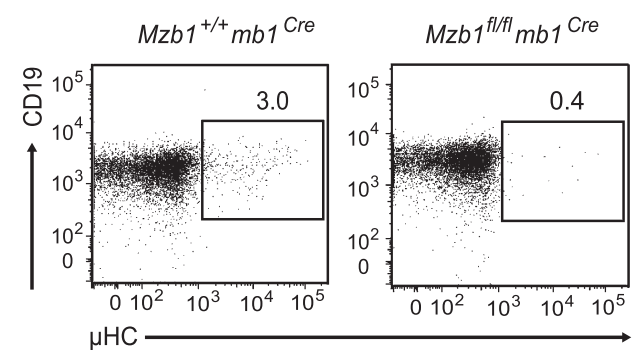

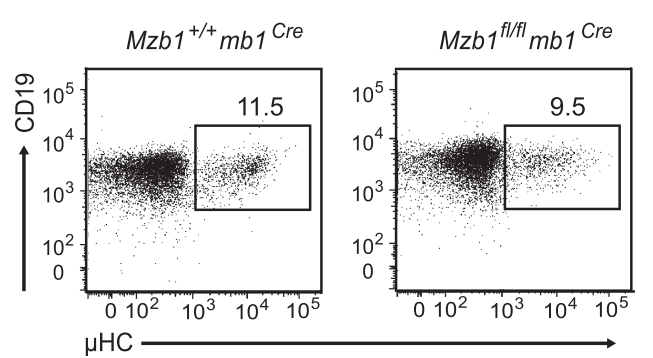

Figure 5. $M z b 1^{f l / f 1} \mathrm{mb1}^{\mathrm{Cre}}$ mice show impaired B-cell differentiation and reduced surface expression of $\mu \mathrm{HCs}$. $(A)$ Flow cytometric profile of the splenic B-cell compartment in $\mathrm{Mzb1}^{+/+} \mathrm{mb1} 1^{\mathrm{Cre}}$ and $\mathrm{Mzb1} 1^{\mathrm{fl} / \mathrm{fl}} \mathrm{mb} 1^{\mathrm{Cre}}$ mice to analyze the frequency of $\mathrm{CD} 19^{+} \mathrm{B}$ cells in the living lymphocyte gate. (B) Flow cytometric profile of $\mathrm{Mzb1}^{+/+} \mathrm{mb1} 1^{\mathrm{Cre}}$ and $\mathrm{Mzb1^{fl/f1 }} \mathrm{mb1}^{\mathrm{Cre}}$ bone marrow cells to detect $\mathrm{B} 22 \mathrm{O}^{+} \mathrm{CD} 43^{+}$ pro-B and early pre-B cells, B220 ${ }^{\text {int }} \mathrm{CD} 43^{-}$late pre-B and immature B cells, and B220hi $\mathrm{CD} 43^{-}$recirculating B cells within the living lymphocyte gate. (C) FACS profile of bone marrow $\mathrm{B} 220^{+} \mathrm{CD} 19^{+}$B cells of $\mathrm{Mzb1} 1^{+/+} \mathrm{mb1} 1^{\mathrm{Cre}}$ and $\mathrm{Mzb1} 1^{f l / f 1} \mathrm{mb1} 1^{\mathrm{Cre}}$ mice gated into $\mu \mathrm{HC}^{-} \mathrm{CD} 25^{-}$pro-B cells, $\mathrm{CD} 25^{+}$pre-B cells, and $\mu \mathrm{HC}^{+} \mathrm{CD} 25^{-}$immature and recirculating B cells. $(D)$ Flow cytometric profile of bone

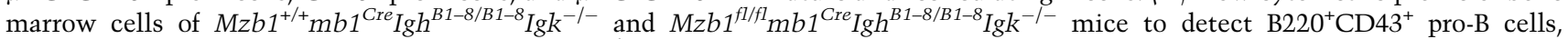
$\mathrm{B} 220^{\text {int }} \mathrm{CD} 43^{-}$pre-B and immature B cells, and B220 ${ }^{\text {hi }} \mathrm{CD} 43^{-}$recirculating B cells within the living lymphocyte gate. Numbers in the FACS profiles show the percentage of cells within the gated population. Data in $A-D$ are representative of five or more independent experiments. (E) FACS profile of $\mathrm{B} 220^{+} \mathrm{CD} 19^{+}$gated B-lineage cells in the bone marrow of $\mathrm{Mzb} 1^{+/+} \mathrm{mb1} 1^{\mathrm{Cre}}$ and $\mathrm{Mzb1} 1^{f l / f l} \mathrm{mb} 1^{\mathrm{Cre}}$ mice to examine the frequency of pre-BCR $\left(\mu \mathrm{HC}^{+} \lambda 5^{+}\right)$cells. Detection of pre-BCR ${ }^{+}$cells was facilitated by an incubation of bone marrow cells for $1 \mathrm{~h}$ at $37^{\circ} \mathrm{C}$ to up-regulate the surface expression of the pre-BCR. Cells were stained with biotinylated anti- $\lambda 5$ antibody followed by fluorochrome-coupled anti-B220, anti-CD19, anti-IgM $\mu$ chain-specific antibodies, and fluorochrome-coupled streptavidin. Numbers indicate the percentage of cells within the $\mathrm{B} 220^{+} \mathrm{CD} 19^{+}$gated population. Data are representative of three independent experiments comprising four or more mice per indicated genotype. $(F)$ Statistical analysis of the frequency of $\mu \mathrm{HC}^{+} \lambda 5^{+}$cells in the B220 $\mathrm{CD} 19^{+}$bone marrow B-cell gate of the biological replicates in the FACS experiment shown in E. Long horizontal bars represent the mean, while short horizontal bars indicate the SD of the mean. Statistical significance between the indicated genotypes was assessed by a two-tailed unpaired Student's $t$-test. Asterisks indicate the statistical significance value. $\left(^{\star \star \star \star}\right) P<0.0001 .(G, H)$ FACS profiles of IL-7 cultured bone marrow-derived B cells of $M z b 1^{+/+} m b 1^{C r e}$ and $M z b 1^{f l / f 1} m b 1^{C r e}$ mice to examine the surface expression $(G)$ and intracellular expression $(H)$ of $\mu \mathrm{HCs}$. The data shown are representative of two experiments. 
Igk rearrangements (Supplemental Fig. S4A,B). These results suggest that these cells have matured; however, the frequency of $\mu \mathrm{HC}^{+} \mathrm{Ig \kappa}^{+}$cells is reduced in $M z b 1^{f l / f 1} \mathrm{IL}-$ 7 B-cell cultures, consistent with the developmental block caused by the impaired surface expression of $\mu \mathrm{HC}$. The phenotype of $M z b 1^{f l / f l} m b 1^{C r e}$ mice raised the question of whether the $m b 1^{C r e}$ allele synergizes with Mzb1 deficiency in pro-B cells. Indeed, flow cytometry of splenic B cells of $M z b 1^{-/-} m b 1^{C r e}$ mice indicated that the number of $\mathrm{CD} 19^{+}$splenic B cells in $\mathrm{Mzb1} 1^{-/} \mathrm{mb1} 1^{\mathrm{Cre}}$ mice is markedly reduced relative to $M z b 1^{-/-}$mice (Fig. 6A).
Moreover, we found reduced percentages of $\mathrm{B} 220^{\mathrm{hi}} \mathrm{CD} 43^{-}$ recirculating $\mathrm{B}$ cells and $\mathrm{B} 22 \mathrm{O}^{\mathrm{int}} \mathrm{CD} 43^{-}$pre-B cells in the bone marrow of $\mathrm{Mzb1}^{-/-} \mathrm{mb1} 1^{\mathrm{Cre}}$ mice (Fig. 6B). In the $m b 1^{C r e}$ deleter strain, the coding sequence of a mammalian codon-optimized humanized Cre recombinase (hCre) gene replaces the endogenous $C D 79 a(\mathrm{mb} 1)$ gene, resulting in heterozygous $m b 1^{+/ C r e}$ mice (Shimshek et al. 2002; Hobeika et al. 2006). Heterozygous $m b 1^{+/ C r e}$ mice have a reduced expression of the $m b 1$ gene product Ig $\alpha$ (Fig. 6C). Therefore, we examined a potential effect of $m b 1$ gene dosage by breeding $M z b 1^{-/-}$mice with mice in which
A

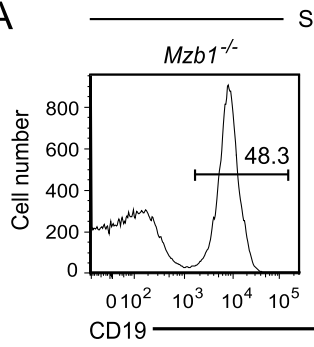

C

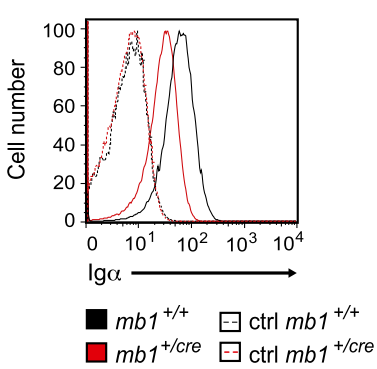

$E$

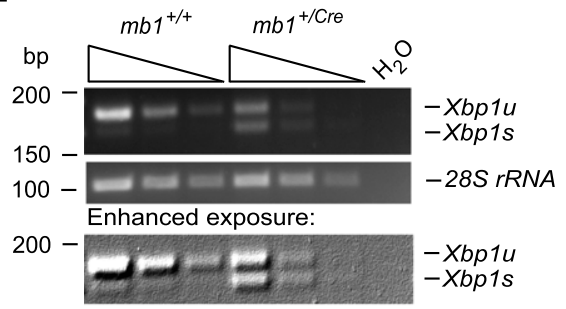

B

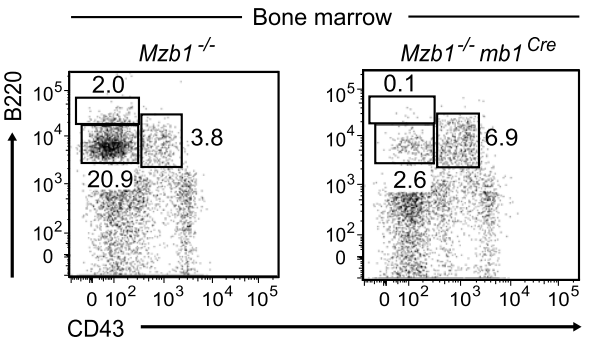

D

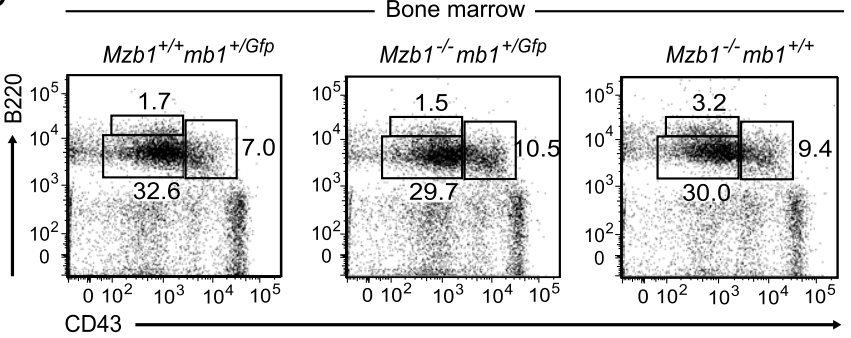

$\mathrm{F}$

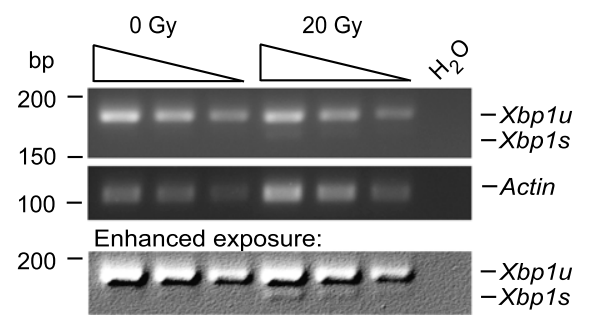

Figure 6. $M b 1^{C r e}$-induced genotoxic stress unmasks a role for MZB1 in pro-B cells. $(A)$ Flow cytometric analysis of splenic cell suspensions of $\mathrm{Mzb1}^{-/-}$and $\mathrm{Mzb1^{-/ }} \mathrm{mb1} 1^{\mathrm{Cre}}$ mice to detect $\mathrm{CD} 19^{+} \mathrm{B}$ cells within the living lymphocyte gate. (B) FACS profile of $\mathrm{Mzb1^{-1- }}$ and $\mathrm{Mzb1^{-1- }} \mathrm{mb1} 1^{\mathrm{Cre}}$ bone marrow cells to detect $\mathrm{B} 220^{+} \mathrm{CD} 43^{+}$pro-B and early pre-B cells, $\mathrm{B} 220^{\text {int }} \mathrm{CD} 43^{-}$late pre-B and immature B cells, and $\mathrm{B} 220^{\text {hi }} \mathrm{CD} 43^{-}$recirculating B cells within the living lymphocyte gate. Data in $A$ and $B$ are representative of four or more experiments. $(C)$ Flow cytometric analysis of $\mathrm{mb1}^{+/+}$(black line) and $\mathrm{mb} 1^{+/ C r e}$ (red line) B220 $\mathrm{CD}^{+} 9^{+}$gated bone marrow cells to detect the intracellular expression level of Ig $\alpha$. Dashed lines represent the respective surface staining with the anti-Ig $\alpha$ antibody. Data are representative of six biological replicates each. (D) Flow cytometric analysis of $M z b 1^{+/+} \mathrm{mb} 1^{+/ G f p}, \mathrm{Mzb1}^{-/-} \mathrm{mb} 1^{+/ G f p}$, and $M z b 1^{-/-} \mathrm{mb1}^{+/+}$mice to examine the percentage of $\mathrm{B} 220^{+} \mathrm{CD} 43^{+}$pro-B and early pre-B cells, $\mathrm{B} 220^{\text {int }} \mathrm{CD} 43^{-}$late pre-B and immature $\mathrm{B}$ cells, and $\mathrm{B} 220^{\mathrm{hi}} \mathrm{CD} 43^{-}$recirculating B cells in the living lymphocyte gate of bone marrow cell suspensions. Data are representative of three or more independent experiments comprising at least two animals per genotype. (E) Semiquantitative RT-PCR to detect transcript levels of $\mathrm{Xbp1u}$ and $\mathrm{Xbp} 1 \mathrm{~s}$ in sorted $\mathrm{B} 22 \mathrm{O}^{+} \mathrm{CD} 43^{+}$pro-B cells of $\mathrm{mb} 1^{+/+}$and $\mathrm{mb} 1^{+/ C r e}$ mice. The expression level of $28 S \mathrm{rRNA}$ served as a loading control. The bottom panel represents an enhanced exposure of the top agarose gel. Triangles indicate 1:3 serial dilutions. Data are representative of three independent experiments. $(F)$ Semiquantitative RT-PCR to detect the expression level of $X b p 1 u$ and Xbp1s in IL-7 cultured pro-B cells irradiated with a dose of either 0 Gy as a control or 20 Gy using a $\gamma$ irradiation source. The transcript level of Actin served as a loading control. The bottom panel represents an enhanced exposure of the top agarose gel. Triangles indicate 1:2 serial dilutions. Data are representative of three experiments. 
a $G f p$ coding sequence is integrated into the endogenous $m b 1$ locus. In $M z b 1^{-/-} m b 1^{+/ G f p}$ mice, we observed similar frequencies of $\mathrm{CD} 19^{+} \mathrm{B}$ cells in the spleen and $\mathrm{B} 220^{\text {int }} \mathrm{CD} 3^{-}$pre-B cells in the bone marrow as compared with $M z b 1^{-/-} \mathrm{mb1}^{+/+}$mice (Fig. 6D). Taken together, these findings suggested that the $m b 1^{C r e}$ allele cooperates with the Mzb1 deficiency to generate a pro-B-cell to pre-B-cell developmental block.

Sustained expression of the Cre recombinase can exert toxic effects on mammalian cells, including chromosomal aberrations and growth arrest (Loonstra et al. 2001; Pfeifer et al. 2001). The Cre-mediated stress response not only is restricted to the nuclear compartment but also involves oxidative stress and lipid peroxidation (Xiao et al. 2012). To address the question of whether the $m b 1^{\text {Cre }}$ allele induces ER stress, we examined the activation of the IRE1 axis of the UPR. Semiquantitative RT-PCR analysis revealed a substantially higher amount of $X b p 1 s$ mRNA in $\mathrm{B} 220^{+} \mathrm{CD}_{4} 3^{+}$pro-B cells of $\mathrm{mb1}{ }^{\mathrm{Cre}}$ mice compared with pro-B cells of $m b 1^{+/+}$mice, suggesting that the $m b 1^{\text {Cre }}$ allele induces an ER stress response (Fig. 6E). To determine whether DNA damage may result in an ER stress response, we irradiated IL-7 cultured wild-type pro-B cells and analyzed the generation of $X b p 1 s$ mRNA. We detected $X b p 1 s$ mRNA in irradiated pro-B cells (Fig. 6F), suggesting that DNA damage induced by Cre expression or $\gamma$ irradiation may also result in ER stress. Thus, naturally occurring ER stress in plasma cells and experimentally induced stress in pro-B cells require the function of MZB1 in enabling proper biosynthesis of $\mu \mathrm{HC}$.

\section{Discussion}

Here, we show that MZB1, a B-lineage-specific ER resident protein, is required for efficient humoral immune responses. Conditional inactivation of $M z b 1$ in the mouse germline or immature B cells revealed defects in the response to T-cell-independent antigens that either bind directly to $\mathrm{MZ} \mathrm{B}$ cells or are scavenged by $\mathrm{CD} 11 \mathrm{c}^{\text {lo }}$ dendritic cells in the blood and are presented to MZ B cells (Guinamard et al. 2000; Balazs et al. 2002). Moreover, the TD response of FoB cells to the antigen TNP-KLH was found to be impaired in MZB1-deficient mice, suggesting a more general function of MZB1 in humoral immune responses. The reduced antibody titers in immunized $M z b 1^{f l / f l} C D 21$-cre mice suggest a B-cell-intrinsic defect because CD21 is almost specifically expressed in B cells (Martin and Weis 1993; Kozono et al. 1998). Moreover, the number of germinal center B cells was not altered in immunized $M z b 1^{f l / f 1} C D 21$-cre mice relative to $\mathrm{Mzb1}^{+/+} \mathrm{CD} 21$-cre control mice (data not shown). Therefore, the decrease in antigen-specific antibody titers in immunized Mzb1-deficient mice could reflect impaired plasma cell differentiation and/or defects in Ig secretion. The expression of transcriptional regulators of plasma cell differentiation, such as Prdm1 (Blimp1) and $X b p 1$, were found to be normal in immunized Mzb1-deficient mice (data not shown). Thus, MZB1 may be dispensable for the early steps of plasma cell differentiation and may be involved in the biosynthesis and secretion of Igs in vivo. In particular, MZB1 regulates both the number of antibody-secreting plasma cells and the efficiency of antibody secretion per cell.

A role of MZB1 in early B lymphopoiesis was also observed in mice in which ER stress or genotoxic stress had been induced by tunicamycin treatment and Cre expression, respectively. Tunicamycin-treated $\mathrm{Mzb1}^{-/-}$ mice and $M z b 1^{f l / f 1} m b 1^{C r e}$ mice both show a block at the transition of pro-B to pre-B cells that is dependent on the expression of a functional pre-BCR. Indeed, we observed an impaired surface expression of $\mu \mathrm{HC}$ in pro-B cells of $M z b 1^{f l / f 1} m b 1^{C r e}$ mice that cannot be accounted for by a defect in rearrangement of the Igh locus. Why does ER stress or genotoxic stress unmask a requirement of MZB1 for $\mu \mathrm{HC}$ surface expression in early but not late stage B cells? In concordance with previous studies, we detected $\mathrm{Xbp} 1 \mathrm{~s}$ transcripts specifically in $\mathrm{B} 220^{+} \mathrm{CD} 43^{+}$ pro-B cells of wild-type mice (Brunsing et al. 2008), indicating that early stage B cells but not mature B cells undergo ER stress. The ER stress in normal pro-B and preB cells may synergize with $M z b 1$ deficiency and unmask a role for MZB1 in proper surface expression of $\mu \mathrm{HC}$ and the pre-BCR.

What could account for the discrepancy of pro-B-cell phenotypes in $M z b 1^{f l / f 1} m b 1^{C r e}$ and $M z b 1^{-/-}$mice? In principle, the heterozygosity of the $m b 1$ allele and reduced expression of Ig $\alpha$ could synergize with the mutant $M z b 1^{f 1}$ allele. However, the combination of a null allele of $M z b 1$ and a mutant $m b 1^{G f p}$ allele did not result in a proB-cell block. Alternatively, augmented ER stress may underlie the mutant phenotype of $M z b 1^{f l / f l} m b 1^{C r e}$ mice. Notably, we found significantly more $X b p 1 s$ transcripts in $m b 1^{C r e}$ pro-B cells, raising the possibility that the $m b 1^{\text {Cre }}$ allele enhances the ER stress normally detected in pro-B cells. Consistent with a potential synergy of the mutant Mzb1 allele and ER stress, tunicamycin treatment of $\mathrm{Mzb1}^{-1-}$ mice was found to mimic the block in pro-B-cell differentiation. Therefore, we favor the view that pro-B cells may be able to cope with the naturally occurring ER stress at this stage of B-cell differentiation but may require the action of additional folding assistants, including GRP94 and MZB1, if any further increase in ER stress occurs. In support of this view, splenic B cells of tunicamycin-treated wild-type mice show an increased association of GRP94 with $\mu \mathrm{HC}$, which is virtually abolished in the absence of MZB1. Interestingly, we could not detect $X b p 1 s$ transcripts in recirculating FoB cells of $M z b 1^{-/-}$mice, suggesting that mature B cells do not experience ER stress and thus may not need MZB1 for proper folding of the membrane-bound IgM. However, differentiation of activated B cells into antibody-secreting plasma cells is accompanied by a natural UPR-mediated ER stress (Gass et al. 2002; Iwakoshi et al. 2003), which may require the function of $\mathrm{MZB} 1$ for the production of functional IgM.

How could the $m b 1^{C r e}$ allele induce ER stress? This Cre allele differs from other Cre alleles by its optimized codon usage, which may result in enhanced expression of Cre and an augmented DNA damage response. Moreover, DNA damage induced by $\gamma$ irradiation was found to result 
in an increase in the numbers of $X b p 1 s$ transcripts. However, the induction of $X b p 1 s$ by $\gamma$ irradiation is modest relative to that induced by tunicamycin or Cre, suggesting that the Cre-mediated toxicity may not be solely via random DNA damage. The mechanism by which DNA damage induces ER stress is still unclear, and therefore it remains plausible that MZB1 has additional functions that are independent of its role in the biosynthesis of $\mu \mathrm{HC}$.

How does MZB1 affect the biosynthesis of $\mu \mathrm{HC}$ ? Previously, we and others found that MZB1 directly associates with the PDI ERp57 and the chaperones BiP and GRP94, suggesting that MZB1 does not act on its own but rather functions in collaboration with folding factors (Shimizu et al. 2009; van Anken et al. 2009; Flach et al. 2010). GRP94 is a substrate-specific chaperone that serves a rather small subset of client proteins, including $\mu \mathrm{HCs}$, TLRs, and integrins (Melnick et al. 1994; Staron et al. 2010; Luo et al. 2011). Notably, we found that the associations of MZB1 with both GRP94 and $\mu \mathrm{HC}$ are markedly enhanced by induction of a UPR in tunicamycin-treated cells. Moreover, the association of GRP94 with its client $\mu \mathrm{HC}$ is critically dependent on the presence of MZB1, as this interaction is reduced and virtually undetectable in unstimulated and tunicamycin-treated MZB1-deficient splenic $B$ cells, respectively. Therefore, we suggest that MZB1 can function as a cochaperone for GRP94 and facilitates its interaction with $\mu \mathrm{HC}$, especially under conditions of ER stress. Although GRP94 is required for the folding and surface expression of TLRs (Staron et al. 2010), this process requires the action of the cochaperone CNPY3, which forms a complex with GRP94 that is sensitive to the presence of ATP (Liu et al. 2010). MZB1 shares with CNPY3 the ATP sensitivity of its interaction with GRP94 and the enhancement of substrate binding to GRP94. However, MZB1-deficient B cells show normal surface expression of TLR4 and LPS responsiveness, indicating that GRP94 may use distinct cochaperones for the folding of immunoglobulins and TLRs. Consistent with this view, knockout of Сnpy3 encoding a cochaperone of GRP94 affects the surface expression of TLRs but does not alter the expression of Igs (Takahashi et al. 2007). In contrast to the inactivation of Cnpy3, which abrogates TLR expression, the effects of $M z b 1$ mutation are less pronounced and are augmented by ER stress and genotoxic stress. This difference could reflect a partially redundant function of MZB1 with other members of the Canopy family of cochaperones.

In conclusion, our data show that MZB1 regulates humoral immune responses and the process of antibody secretion in vivo. In particular, MZB1 is needed for the proper biosynthesis of $\mu \mathrm{HCs}$ under conditions of natural and experimentally induced ER stress, including pharmacologically or genetically induced ER stress. MZB1 associates directly with the substrate-specific chaperone GRP94, and MZB1 is required for the interaction of $\mu \mathrm{HCs}$ with GRP94 under ER stress, suggesting that MZB1 acts as a substrate-specific cochaperone of GRP94.

\section{Materials and methods}

Mice

All mouse experiments were carried out in accordance with the guidelines of the Federation of European Laboratory Animal Science Association (FELASA) and following legal approval of the Regierungspräsidium Freiburg. $M z b 1^{+/ f \text {; neo }}$ chimeric mice were generated in the transgenic facility of the Max Planck Institute of Immunobiology and Epigenetics by Benoît Kanzler. ACT-FLPe mice (Susan Dymecki, Harvard Medical School) were ordered from Jackson Laboratories, while Slp $65^{-/-}, \mathrm{mb1} 1^{\mathrm{Cre}}$, and $\mathrm{mb1^{+/Gfp }}$ mice were provided by the laboratory of Michael Reth (AlbertLudwigs-University Freiburg). Igh ${ }^{B 1-8 / B 1-8} \mathrm{Igk}^{-/-}, C M V$-cre, and CD21-cre animals were obtained from the laboratory of Klaus Rajewsky (Max-Delbrück-Center for Molecular Medicine). Mouse strains were bred and maintained in the institute's conventional animal care facility and genotyped using the appropriate primers. For experiments, animals were backcrossed for at least six generations onto a 129S2/SvPas or C57BL/6J (Jackson Laboratories) background. Unless otherwise stated, experiments were performed in a C57BL/6J background.

\section{Flow cytometry}

Cells were blocked with $\alpha$-CD16/32 clone 93 (BD Pharmingen) and stained with the following fluorochrome-coupled antibodies purchased from either eBioscience or BD Pharmingen: $\alpha$-AA4.1 clone AA4.1, $\alpha$-B220 clone RA3-6B2, $\alpha$-BP1 clone BP-1, $\alpha$-CD5 clone 537.3, $\alpha$-CD16/32 clone 93, $\alpha$-CD19 clone 1D3, $\alpha$-CD21 clone 7G6, $\alpha$-CD23 clone B3B4, $\alpha$-CD38 clone 90/CD38, $\alpha$-CD43 clone S7, $\alpha$ CD138 clone 281-2, $\alpha$-HSA clone M1/69, $\alpha-\operatorname{Ig} \alpha$ clone $24 \mathrm{C} 2.5, \alpha-\lambda 5$ clone LM34, $\alpha$-IgG1 clone R3-3, $\alpha$-GL7 clone GL7, $\alpha$-Igк clone 187.1, NP-PE (Biosearch Technologies), streptavidin-PE (\#554061, BD Pharmingen), streptavidin-APC (\#554067, BD Pharmingen), $\alpha$-IgM $\mu$-APC (\#115-175-075, Jackson ImmunoResearch Europe), and IgM $\mu$-PE (\#1020-09S, SouthernBiotech). The stained cells were then subjected to FACS analysis on a special-order LSR II equipped with a UV, a violet, and a yellow-green laser (BD Biosciences) or sorted with either a BD Influx or a BD FACSAria III (BD Biosciences). For intracellular FACS staining, the BD Cytofix/ Cytoperm kit (BD Biosciences) was employed, and, in the case of surface $\mu \mathrm{HCs}$, the surface was blocked with $10 \mu \mathrm{g}$ of unlabeled $\alpha-\operatorname{IgM} \mu(\# 31172$, Thermo Fisher Scientific). MACS purification of splenic $\mathrm{CD} 9^{+}$cells was performed using CD19 Microbeads (Miltenyi) according to the manufacturer's protocol.

\section{Immunizations and ELISA}

TD antigen TNP(12)-KLH (Biosearch Technologies) was adsorbed overnight in a 1:1 ratio onto Alu-Gel-S (Serva). Mice were either intraperitoneally injected with $150 \mu \mathrm{g}$ of adsorbed TNP(12)-KLH (Biosearch Technologies) or immunized with $25 \mu \mathrm{g}$ of T-cellindependent antigen TNP(27)-Ficoll (Biosearch Technologies) or $0.5 \mu \mathrm{g}$ of S.p. PS (American Type Culture Collection [ATCC]) by intravenous injection into the lateral tail vein. Blood was collected into SST Microtainer tubes (BD) and agglutinated. Pure serum was then obtained by a centrifugation step of $1500 \mathrm{~g}$. ELISA plates (Corning) were coated overnight with $10 \mu \mathrm{g} / \mathrm{mL}$ TNP-BSA (Biosearch Technologies), S.p. PS (ATCC), or $\alpha$-mouse $\operatorname{IgM}$ (Thermo Fisher Scientific) in PBS. The next day, plates were washed under tap water and blocked for $1.5 \mathrm{~h}$ with PBS/0.5\% BSA. After removal of the blocking solution, 1:100 dilutions of mouse sera were serially diluted in duplicate with an appropriate standard (mouse $\alpha$-TNP-IgM; \#55581, BD Pharmingen) or a reference sample. For primary B-cell ELISA, an undiluted supernatant 
of $2 \mu \mathrm{g} / \mathrm{mL}$ LPS-stimulated (Sigma) MZ B cells that had been counted after $48 \mathrm{~h}$ and plated out in triplicate overnight was employed, with unlabeled mouse IgM (SouthernBiotech) as a standard. The plates were incubated for $1 \mathrm{~h}$ at $37^{\circ} \mathrm{C}$, washed under tap water, and incubated with a 1:1000 dilution of the appropriate biotinylated secondary antibody (SouthernBiotech) for $1 \mathrm{~h}$ at $37^{\circ} \mathrm{C}$. Following three washing steps under tap water, plates were incubated with a 1:3000 dilution of streptavidinalkaline phosphatase (SouthernBiotech) for $1 \mathrm{~h}$ at room temperature. Subsequently, plates were washed under tap water and developed by addition of ELISA substrate buffer (52.57 $\mathrm{g}$ of diethanolamine, $400 \mathrm{mg}$ of $\mathrm{MgCl}_{2} \times 6 \mathrm{H}_{2} \mathrm{O}, 100 \mathrm{mg}$ of $\mathrm{NaN}_{3}$ at $\mathrm{pH} 9.6,500 \mathrm{~mL}$ of $\mathrm{ddH}_{2} \mathrm{O}$ ). Enzymatic reaction was stopped by addition of $4 \mathrm{~N} \mathrm{NaOH}$, and plates were read out using a Spectramax 250 ELISA reader (Molecular Devices).

\section{ER stress induction}

In vivo, ER stress was pharmacologically induced by intraperitoneal injection of $10 \mu \mathrm{g}$ of tunicamycin per gram of body weight (Enzo Life Sciences) in $150 \mathrm{mM}$ glucose for $12 \mathrm{~h}$, while in cell culture, cells were treated with $5 \mu \mathrm{g} / \mathrm{mL}$ tunicamycin for $8 \mathrm{~h}$.

\section{$\gamma$ Irradiation of cell culture cells}

IL-7 cultured pro-B cells were irradiated with a dose of $20 \mathrm{~Gy}$ in a cell culture dish using a $\gamma$ irradiator with a ${ }^{137} \mathrm{Cs}$ source (Biobeam GM 8000, Gamma Service Medical GmbH) and incubated for $5 \mathrm{~h}$ at $37^{\circ} \mathrm{C}$ with $5 \% \mathrm{CO}_{2}$. Following the purification of living cells by a Ficoll gradient, cells were subjected to RNA preparation.

\section{$m R N A$ preparation and (semi)quantitative $R T-P C R$}

mRNA preparation was performed using Trizol reagent (Life Technologies), and cDNA was subsequently prepared using SuperScript II reverse transcriptase (Invitrogen, Life Technologies) according to the manufacturer's protocol. One microliter of cDNA was mixed with $1 \times$ final concentration of Fast SYBR Green Master Mix (Applied Biosystems, Life Technologies) and 0.2 $\mathrm{pmol} / \mu \mathrm{L}$ final concentration of respective forward and reverse primers in a total volume of $10 \mu \mathrm{L}$ in an Applied Biosystems MicroAmp optical 96-well plate. The reaction was performed in an Applied Biosystems 7500 Fast real-time PCR machine. For semiquantitative RT-PCR, the reaction was performed in 0.2-mL PCR tubes (Biozym) using HT Master Taq polymerase, $0.2 \mathrm{mM}$ dNTPs, MgCl-containing PCR buffer /Genaxxon Bioscience), and $1.5 \mu \mathrm{M}$ forward and reverse primers.

\section{Co-IP and immunoblot analysis}

Cells were washed three times with $1 \mathrm{~mL}$ of cold PBS and resuspended in an appropriate cell number-dependent volume of immunoprecipitation buffer 1 containing $20 \mathrm{mM}$ HEPES-KOH (pH 7.6), $2 \mathrm{mM} \mathrm{MgCl} 2,150 \mathrm{mM} \mathrm{NaCl}, 5 \%$ glycerol, $0.1 \%$ NP40, $1 \mathrm{mM} \mathrm{Na}_{3} \mathrm{VO}_{4}, 1 \mathrm{mM}$ PMSF, $1 \times$ homemade protease inhibitor $\mathrm{mix}$, and $10 \mathrm{mM} \mathrm{NaF}$. Following sonication in a prechilled Branson 450 water bath sonifier, the cell lysate was centrifuged at $16,100 \mathrm{~g}$ for $10 \mathrm{~min}$ at $4^{\circ} \mathrm{C}$. The protein concentration of the supernatant was measured by a Bradford assay, and $1 \mathrm{mg}$ of total protein was then mixed with $\alpha$-MZB1 or $\alpha$-rat IgG2a isotype control (Southern Biotech) linked to sepharose beads (GE Healthcare) or with $\alpha$-GRP94 ab13509 (Abcam) or rabbit IgG control (Bethyl Laboratories) together with equilibrated Protein G sepharose beads (GE Healthcare) and rotated end over end for $4 \mathrm{~h}$ at $4^{\circ} \mathrm{C}$. Subsequently, beads were washed three times with immunoprecipitation buffer 1 and once with immunoprecipitation buffer 1 containing $500 \mathrm{mM} \mathrm{NaCl}$. Associated proteins were eluted by addition of $2 \times$ sample buffer and a boiling step of $10 \mathrm{~min}$ at $95^{\circ} \mathrm{C}$. Following separation of the proteins by SDS-PAGE, proteins were detected by the following antibodies: $\alpha$-MZB1 clone 2F9 (Flach et al. 2010), $\alpha$-GAPDH clone 6C5 (Calbiochem, Merck Millipore), $\alpha$-GRP94 (\#2104S, Cell Signaling), peroxidase-conjugated $\alpha$-mouseIgM $\mu, \alpha$-mouse-IgG, $\alpha$-rabbit-IgG, and $\alpha$-rat-IgG (Jackson ImmunoResearch Europe). Blots were developed with SuperSignal WestPico or WestFemto (Thermo Fisher Scientific).

For the in vitro immunopurification assay, murine GRP94 was purified from mouse livers as previously described ( $\mathrm{Li}$ and Srivastava 1993) and incubated end over end with recombinantly purified MZB1 (Flach et al. 2010) and increasing concentrations of ATP or AMP-PNP (Sigma) for $2 \mathrm{~h}$ at $4^{\circ} \mathrm{C}$ in the presence of antiMZB1 monoclonal antibody coupled to sepharose beads. Following three washes with immunoprecipitation buffer 1, proteins were eluted and analyzed by SDS-PAGE and immunoblotting.

\section{Statistical analysis}

Microsoft Excel or GraphPad Prism 6.0b software was used to calculate mean and standard deviation of the mean, while the GraphPad Prism 6.0b software was employed for testing statistical significance by an unpaired two-tailed Student's $t$-test with a significance level of $\alpha=0.05$. For quantification of semiquantitative RT-PCR, the ImageJ program (version 1.47) was employed.

\section{Acknowledgments}

We thank Ingrid Falk for expert technical help, Benoit Kanzler for injection of ES cells, and Uta Stauffer for tail vein injections. We are also grateful to Klaus Rajewsky (Max-Delbrück-Center, Berlin) and Michael Reth (Max Planck Insitute for Immunbiology and Epigenetics, Freiburg) for generously providing CD21-Cre and $m b 1^{\text {Cre }}$ mice, respectively. We thank Michael Reth and Elias Hobeika for discussions and advice. We thank Minh Nguyen and Matthias Mayer (Zentrum für Molekulare Biologie der Universität Heidelberg, Heidelberg) for help with the enzymatic ATPase activity assay. This work was supported by funds of the Max Planck Society.

\section{References}

Allman D, Pillai S. 2008. Peripheral B cell subsets. Curr Opin Immunol 20: 149-157.

Attanavanich K, Kearney JF. 2004. Marginal zone, but not follicular B cells, are potent activators of naive CD4 T cells. J Immunol 172: 803-811.

Balazs M, Martin F, Zhou T, Kearney J. 2002. Blood dendritic cells interact with splenic marginal zone B cells to initiate T-independent immune responses. Immunity 17: 341352.

Bertolotti A, Zhang Y, Hendershot LM, Harding HP, Ron D. 2000. Dynamic interaction of $\mathrm{BiP}$ and ER stress transducers in the unfolded-protein response. Nat Cell Biol 2: 326-332.

Bonfoco E, Li E, Kolbinger F, Cooper NR. 2001. Characterization of a novel proapoptotic caspase-2- and caspase-9-binding protein. J Biol Chem 276: 29242-29250.

Brouns GS, de Vries E, Neefjes JJ, Borst J. 1996. Assembled pre-B cell receptor complexes are retained in the endoplasmic reticulum by a mechanism that is not selective for the pseudo-light chain. J Biol Chem 271: 19272-19278.

Brunsing R, Omori SA, Weber F, Bicknell A, Friend L, Rickert R, Niwa M. 2008. B- and T-cell development both involve activity of the unfolded protein response pathway. I Biol Chem 283: 17954-17961. 
Bruyn GA, Zegers BJ, van Furth R. 1992. Mechanisms of host defense against infection with Streptococcus pneumoniae. Clin Infect Dis 14: 251-262.

Calfon M, Zeng H, Urano F, Till JH, Hubbard SR, Harding HP, Clark SG, Ron D. 2002. IRE1 couples endoplasmic reticulum load to secretory capacity by processing the XBP-1 mRNA. Nature 415: 92-96.

Constant S, Schweitzer N, West J, Ranney P, Bottomly K. 1995. B lymphocytes can be competent antigen-presenting cells for priming $\mathrm{CD}^{+} \mathrm{T}$ cells to protein antigens in vivo. J Immunol 155: 3734-3741.

Eferl R, Hoebertz A, Schilling AF, Rath M, Karreth F, Kenner L, Amling M, Wagner EF. 2004. The Fos-related antigen Fra- 1 is an activator of bone matrix formation. EMBO J 23: 27892799.

Flach H, Rosenbaum M, Duchniewicz M, Kim S, Zhang SL, Cahalan MD, Mittler G, Grosschedl R. 2010. Mzb1 protein regulates calcium homeostasis, antibody secretion, and integrin activation in innate-like B cells. Immunity 33: 723-735.

Flemming A, Brummer T, Reth M, Jumaa H. 2003. The adaptor protein SLP-65 acts as a tumor suppressor that limits pre-B cell expansion. Nat Immunol 4: 38-43.

Gass JN, Gifford NM, Brewer JW. 2002. Activation of an unfolded protein response during differentiation of antibody-secreting B cells. J Biol Chem 277: 49047-49054.

Guinamard R, Okigaki M, Schlessinger J, Ravetch JV. 2000. Absence of marginal zone B cells in Pyk-2-deficient mice defines their role in the humoral response. Nat Immunol 1: 31-36.

Haas IG, Wabl M. 1983. Immunoglobulin heavy chain binding protein. Nature 306: 387-389.

Han J, Back SH, Hur J, Lin YH, Gildersleeve R, Shan J, Yuan CL, Krokowski D, Wang S, Hatzoglou M, et al. 2013. ER-stressinduced transcriptional regulation increases protein synthesis leading to cell death. Nat Cell Biol 15: 481-490.

Herzog S, Jumaa H. 2012. Self-recognition and clonal selection: autoreactivity drives the generation of B cells. Curr Opin Immunol 24: 166-172.

Hobeika E, Thiemann S, Storch B, Jumaa H, Nielsen PJ, Pelanda R, Reth M. 2006. Testing gene function early in the B cell lineage in mbl-cre mice. Proc Natl Acad Sci 103: 1378913794.

Iwakoshi NN, Lee AH, Vallabhajosyula P, Otipoby KL, Rajewsky K, Glimcher LH. 2003. Plasma cell differentiation and the unfolded protein response intersect at the transcription factor XBP-1. Nat Immunol 4: 321-329.

Jumaa H, Wollscheid B, Mitterer M, Wienands J, Reth M, Nielsen PJ. 1999. Abnormal development and function of B lymphocytes in mice deficient for the signaling adaptor protein SLP-65. Immunity 11: 547-554.

Karasuyama H, Rolink A, Shinkai Y, Young F, Alt FW, Melchers F. 1994. The expression of Vpre-B/ $\lambda 5$ surrogate light chain in early bone marrow precursor B cells of normal and B celldeficient mutant mice. Cell 77: 133-143.

Kitamura D, Roes J, Kuhn R, Rajewsky K. 1991. A B celldeficient mouse by targeted disruption of the membrane exon of the immunoglobulin $\mu$ chain gene. Nature 350: 423426.

Kitamura D, Kudo A, Schaal S, Muller W, Melchers F, Rajewsky K. 1992. A critical role of $\lambda 5$ protein in B cell development. Cell 69: 823-831.

Kozono Y, Abe R, Kozono H, Kelly RG, Azuma T, Holers VM. 1998. Cross-linking CD21/CD35 or CD19 increases both B71 and B7-2 expression on murine splenic B cells. I Immunol 160: $1565-1572$.
Kraus M, Alimzhanov MB, Rajewsky N, Rajewsky K. 2004. Survival of resting mature B lymphocytes depends on BCR signaling via the $\operatorname{Ig} \alpha / \beta$ heterodimer. Cell 117: 787-800.

Li Z, Srivastava PK. 1993. Tumor rejection antigen gp96/grp94 is an ATPase: implications for protein folding and antigen presentation. EMBO J 12: 3143-3151.

Lilie H, McLaughlin S, Freedman R, Buchner J. 1994. Influence of protein disulfide isomerase (PDI) on antibody folding in vitro. J Biol Chem 269: 14290-14296.

Liu B, Yang Y, Qiu Z, Staron M, Hong F, Li Y, Wu S, Li Y, Hao B, Bona R, et al. 2010. Folding of Toll-like receptors by the HSP90 paralogue gp96 requires a substrate-specific cochaperone. Nature communications 1: 79.

Loonstra A, Vooijs M, Beverloo HB, Allak BA, van Drunen E, Kanaar R, Berns A, Jonkers J. 2001. Growth inhibition and DNA damage induced by Cre recombinase in mammalian cells. Proc Natl Acad Sci 98: 9209-9214.

Luo B, Lam BS, Lee SH, Wey S, Zhou H, Wang M, Chen SY, Adams GB, Lee AS. 2011. The endoplasmic reticulum chaperone protein GRP94 is required for maintaining hematopoietic stem cell interactions with the adult bone marrow niche. PLOS ONE 6: e20364.

Martin BK, Weis JH. 1993. Murine macrophages lack expression of the Cr2-145 (CR2) and Cr2-190 (CR1) gene products. Eur I Immunol 23: 3037-3042.

Martin F, Oliver AM, Kearney JF. 2001. Marginal zone and B1 B cells unite in the early response against T-independent blood-borne particulate antigens. Immunity 14: 617-629.

Melnick J, Dul JL, Argon Y. 1994. Sequential interaction of the chaperones BiP and GRP94 with immunoglobulin chains in the endoplasmic reticulum. Nature 370: 373-375.

Meunier L, Usherwood YK, Chung KT, Hendershot LM. 2002. A subset of chaperones and folding enzymes form multiprotein complexes in endoplasmic reticulum to bind nascent proteins. Mol Biol Cell 13: 4456-4469.

Mielenz D, Ruschel A, Vettermann C, Jack HM. 2003. Immunoglobulin $\mu$ heavy chains do not mediate tyrosine phosphorylation of Ig $\alpha$ from the ER-cis-Golgi. I Immunol 171: 3091-3101.

Niu H, Ye BH, Dalla-Favera R. 1998. Antigen receptor signaling induces MAP kinase-mediated phosphorylation and degradation of the BCL-6 transcription factor. Genes Dev 12: 1953-1961.

Oliver AM, Martin F, Gartland GL, Carter RH, Kearney JF. 1997. Marginal zone B cells exhibit unique activation, proliferative and immunoglobulin secretory responses. Eur I Immunol 27: 2366-2374.

Pfeifer A, Brandon EP, Kootstra N, Gage FH, Verma IM. 2001. Delivery of the Cre recombinase by a self-deleting lentiviral vector: efficient gene targeting in vivo. Proc Natl Acad Sci 98: $11450-11455$.

Reimold AM, Iwakoshi NN, Manis J, Vallabhajosyula $\mathrm{P}$, Szomolanyi-Tsuda E, Gravallese EM, Friend D, Grusby MJ, Alt F, Glimcher LH. 2001. Plasma cell differentiation requires the transcription factor XBP-1. Nature 412: 300-307.

Rijkers GT, Mosier DE. 1985. Pneumococcal polysaccharides induce antibody formation by human B lymphocytes in vitro. J Immunol 135: 1-4.

Rodriguez CI, Buchholz F, Galloway J, Sequerra R, Kasper J, Ayala R, Stewart AF, Dymecki SM. 2000. High-efficiency deleter mice show that FLPe is an alternative to Cre-loxP. Nat Genet 25: 139-140.

Schwenk F, Baron U, Rajewsky K. 1995. A cre-transgenic mouse strain for the ubiquitous deletion of loxP-flanked gene segments including deletion in germ cells. Nucleic Acids Res 23: 5080-5081. 
Shaffer AL, Shapiro-Shelef M, Iwakoshi NN, Lee AH, Qian SB, Zhao H, Yu X, Yang L, Tan BK, Rosenwald A, et al. 2004. $\mathrm{XBP1}$, downstream of Blimp-1, expands the secretory apparatus and other organelles, and increases protein synthesis in plasma cell differentiation. Immunity 21: 81-93.

Shimizu Y, Meunier L, Hendershot LM. 2009. pERp1 is significantly up-regulated during plasma cell differentiation and contributes to the oxidative folding of immunoglobulin. Proc Natl Acad Sci 106: 17013-17018.

Shimshek DR, Kim J, Hubner MR, Spergel DJ, Buchholz F, Casanova E, Stewart AF, Seeburg PH, Sprengel R. 2002. Codon-improved Cre recombinase (iCre) expression in the mouse. Genesis 32: 19-26.

Sonoda E, Pewzner-Jung Y, Schwers S, Taki S, Jung S, Eilat D, Rajewsky K. 1997. B cell development under the condition of allelic inclusion. Immunity 6: 225-233.

Staron M, Yang Y, Liu B, Li J, Shen Y, Zuniga-Pflucker JC, Aguila HL, Goldschneider I, Li Z. 2010. gp96, an endoplasmic reticulum master chaperone for integrins and Toll-like receptors, selectively regulates early $\mathrm{T}$ and $\mathrm{B}$ lymphopoiesis. Blood 115: 2380-2390.

Takahashi K, Shibata T, Akashi-Takamura S, Kiyokawa T, Wakabayashi Y, Tanimura N, Kobayashi T, Matsumoto F, Fukui R, Kouro T, et al. 2007. A protein associated with Tolllike receptor (TLR) 4 (PRAT4A) is required for TLR-dependent immune responses. J Exp Med 204: 2963-2976.

Takeda S, Zou YR, Bluethmann H, Kitamura D, Muller U, Rajewsky K. 1993. Deletion of the immunoglobulin $\kappa$ chain intron enhancer abolishes $\kappa$ chain gene rearrangement in cis but not $\lambda$ chain gene rearrangement in trans. EMBO $J$ 12: 2329-2336.

Taubenheim N, Tarlinton DM, Crawford S, Corcoran LM, Hodgkin PD, Nutt SL. 2012. High rate of antibody secretion is not integral to plasma cell differentiation as revealed by XBP-1 deficiency. J Immunol 189: 3328-3338.

Todd DI, Lee AH, Glimcher LH. 2008. The endoplasmic reticulum stress response in immunity and autoimmunity. Nat Rev Immunol 8: 663-674.

van Anken E, Romijn EP, Maggioni C, Mezghrani A, Sitia R, Braakman I, Heck AJ. 2003. Sequential waves of functionally related proteins are expressed when B cells prepare for antibody secretion. Immunity 18: 243-253.

van Anken E, Pena F, Hafkemeijer N, Christis C, Romijn EP, Grauschopf U, Oorschot VM, Pertel T, Engels S, Ora A, et al. 2009. Efficient IgM assembly and secretion require the plasma cell induced endoplasmic reticulum protein pERp1. Proc Natl Acad Sci 106: 17019-17024.

Vavassori S, Cortini M, Masui S, Sannino S, Anelli T, Caserta IR, Fagioli C, Mossuto MF, Fornili A, van Anken E, et al. 2013. A $\mathrm{pH}$-regulated quality control cycle for surveillance of secretory protein assembly. Mol Cell 50: 783-792.

von Boehmer H, Melchers F. 2010. Checkpoints in lymphocyte development and autoimmune disease. Nat Immunol 11: 14-20.

Winkler TH, Rolink A, Melchers F, Karasuyama H. 1995. Precursor B cells of mouse bone marrow express two different complexes with the surrogate light chain on the surface. Eur I Immunol 25: 446-450.

Xiao Y, Karnati S, Qian G, Nenicu A, Fan W, Tchatalbachev S, Holand A, Hossain H, Guillou F, Luers GH, et al. 2012. Cremediated stress affects sirtuin expression levels, peroxisome biogenesis and metabolism, antioxidant and proinflammatory signaling pathways. PLOS ONE 7: e41097.

Yoshida H, Matsui T, Yamamoto A, Okada T, Mori K. 2001. XBP1 mRNA is induced by ATF6 and spliced by IRE1 in response to ER stress to produce a highly active transcription factor. Cell 107: 881-891.
Zheng Y, Yu M, Podd A, Yuan L, Newman DK, Wen R, Arepally G, Wang D. 2013. Critical role for mouse marginal zone B cells in PF4/heparin antibody production. Blood 121: 34843492.

Zinszner H, Kuroda M, Wang X, Batchvarova N, Lightfoot RT, Remotti H, Stevens JL, Ron D. 1998. CHOP is implicated in programmed cell death in response to impaired function of the endoplasmic reticulum. Genes Dev 12: 982-995. 


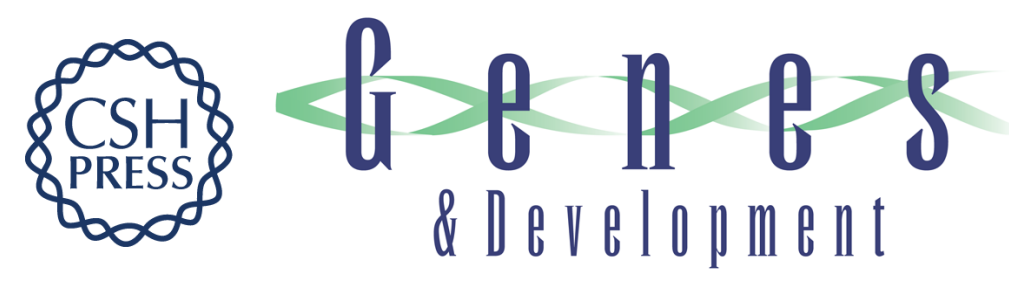

\section{MZB1 is a GRP94 cochaperone that enables proper immunoglobulin heavy chain biosynthesis upon ER stress}

Marc Rosenbaum, Virginia Andreani, Tanya Kapoor, et al.

Genes Dev. 2014, 28:

Access the most recent version at doi:10.1101/gad.240762.114

\section{Supplemental http://genesdev.cshlp.org/content/suppl/2014/05/28/28.11.1165.DC1 Material}

References This article cites 61 articles, 23 of which can be accessed free at: http://genesdev.cshlp.org/content/28/11/1165.full.html\#ref-list-1

Creative This article, published in Genes \& Development, is available under a Creative Commons Commons License (Attribution-NonCommercial 4.0 International), as described at License http://creativecommons.org/licenses/by-nc/4.0/.

Email Alerting Receive free email alerts when new articles cite this article - sign up in the box at the top Service right corner of the article or click here.

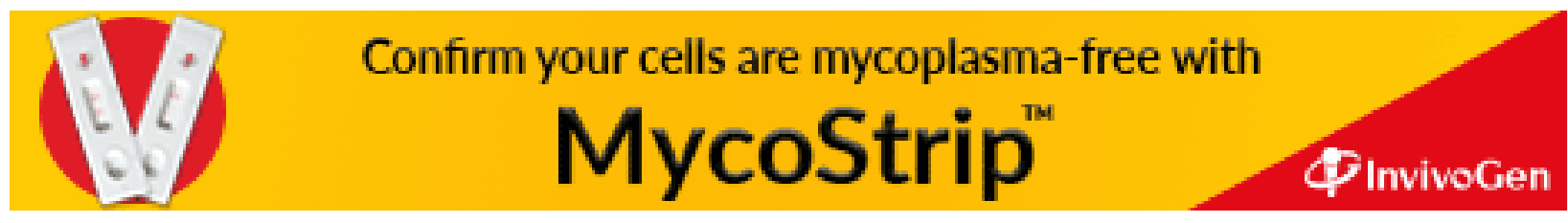

